Antonis Iliopoulos*

\title{
Early body ornamentation as Ego-culture: Tracing the co-evolution of aesthetic ideals and cultural identity
}

https://doi.org/10.1515/sem-2019-0073

\begin{abstract}
While the "symbolic" meaning of early body ornamentation has received the lion's share of attention in the debate on human origins, this paper sets out to explore their aesthetic and agentive dimensions, for the purpose of explaining how various ornamental forms would have led interacting groups to form a cultural identity of their own. To this end, semiotics is integrated with a new paradigm in the archaeology of mind, known as the theory of material engagement. Bridging specifically Peirce's pragmatic theory and Malafouris' enactive take on aesthetics allows us to appreciate the formation of aesthetic ideals through the agentive effects of material signs. It is thus proposed that, by attending to the interrelation between form, effect, and affect, members of social groups would have come to appreciate the ways in which their ornamental culture resembles and differs from that of neighbouring groups. Following the Lund conception of cultural semiotics, I argue that models of Ego-culture would have come to evolve along Alter-cultures that also employ ornaments, and against Alius-cultures that have yet to develop or adopt personal decoration. The aesthetic ideals associated with early body ornaments must have therefore played a catalytic role in the formation and communication of group membership. I thus close by proposing that the origins of new cultural identities can be explained by tracing the co-development of ideas and ideals.
\end{abstract}

Keywords: material signs, body ornaments, aesthetics, cultural identity, cognitive evolution, semiotic scaffolding

\section{Introduction: Focusing on "symbolism"}

A review of the literature on human origins quickly reveals that the field of evolutionary cognitive archaeology has long been dominated by a trait-list approach used by prehistorians searching for proxies of "modern" human

*Corresponding author: Antonis Iliopoulos, Institute of Archaeology, School of Archaeology, University of Oxford, 36 Beaumont St, Oxford, UK, E-mail: antonis.iliopoulos@keble.oxon.org http://orcid.org/0000-0001-8231-9194 
behavior and by extension, cognition. While there is no set list of criteria that allow us to detect "humans like us" in the archaeological record, a typical range of sapient practices includes: worked bone and antler, blade technology, standardisation of artefact types and artefact diversity, complex hearth construction, organized use of domestic space, expanded exchange networks, effective largemammal exploitation, seasonally focused mobility strategies, use of harsh environments, fishing, and of course what are generally viewed as "symbolic" proxies - that is, the burial of the dead as an indicator of ritual, ochre pigments, personal ornaments, and art (Henshilwood and Marean 2003). What makes these forms of material culture "symbolic" in the eyes of archaeologists is that they represent or stand for something (concrete or abstract) that is not immediately present. "Symbolism" then corresponds to what semioticians broadly call "signification." Keeping in mind the role that signs play in defining the human condition, it should come to no surprise that archaeologists tend to accept "symbolic" behavior as the crux of "modernity" (e.g. Chase and Dibble 1987: 264; d'Errico et al. 2005: 4; Henshilwood and Marean 2003: 635; Nowell 2010: 447; Pettitt 2011: 142; Shea 2011: 8).

Material "symbols" are widely considered indispensable for the "modern" human mind because they allowed humans to store concepts outside of the human brain (d'Errico et al. 2003; Henshilwood and Marean 2003). As would be expected, the ability of artefacts to function as external storage media for predefined meanings made them prime candidates for the communication of messages to anyone able to decode them through the use of shared knowledge. In effect, many archaeologists have tried to elucidate the nature of "symbols" by using the term to denote any object or practice considered to have been bestowed at some point with arbitrary and conventionally-agreed upon meaning. This brings us to another reason why material "symbols" are so important to archaeologists: for such tacit agreements to have been made in the first place and assimilated later on, "modern" language must have been a necessary prerequisite (d'Errico et al. 2003; Henshilwood and Marean 2003). According to d'Errico and his colleagues (2003: 31), "modern language is the only communication system with a 'built-in' metalanguage that allows for the creation of symbolic codes." On the count then that these codes would have had to be underpinned by the capacity for both material and verbal forms of "symbolism," archaeologists usually associate artefacts that did not serve subsistence/settlement purposes with representation and communication.

As mentioned above, prehistoric ornamental beads are one kind of "symbolic" material culture, and are as such considered an undisputed proxy for "modern" cognitive abilities (e. g. Vanhaeren and d'Errico 2006; White 2007; Bednarik 2008; d' Errico et al. 2008; Fernández and Jöris 2008; d'Errico and Vanhaeren 2009; 
Barton and d'Errico 2012; also see Abadía and Nowell 2015: 965-966). This view has been deeply entrenched in archaeological thinking from the time the discussion was still focused on the younger Upper Palaeolithic (UP) ornaments of Europe (Klein 2000; Kuhn et al. 2001; Bar-Yosef 2002; White 1989). At the turn of the millennium, Wadley (2001: 203) characteristically reported that "[p]robably all archaeologists are agreed that the presence of / ... / personal ornaments represents symbolic and therefore culturally modern behaviour." According to the archaeological consensus, early body ornaments were deliberately produced by "symbolically"-capable brains for the purpose of communicating "symbolically"-coded information. The wearers of these artefacts relied on code-dictated style to signify their cultural identity, for instance. Wadley's (2001: 208) words are particular telling of this commonplace stance: "Jewellery can be seen as style that could signify a form of cultural identity. Ornamentation provides information about its wearer; this information is a culture-specific code. It might be impossible for archaeologists to crack the code, but it is not difficult to recognize its symbolic content."

This "symbolocentric" way of thinking was maintained in the following years, when older shell beads recovered from Middle Stone Age (MSA) layers of Blombos Cave came to change what we thought of as the time and place of "modern" human origins. In presenting the perforated tick shells discovered in South Africa, Henshilwood and his colleagues (2004: 404) argued that "[t]he discovery of personal ornaments in the 75-ka [thousand year ago] levels of Blombos Cave adds an unambiguous marker of symbolically mediated behavior to the list of innovations already identified in the MSA." They were adamant that "[i]n human societies, beads have many different functions, all eminently symbolic" (Henshilwood et al. 2004: 404). Based on the supposition that the shell beads retrieved had been used by the inhabitants of the cave as "symbolic" ornaments whose meaning was based on conventions shared through language, it was confidently suggested that language and fully "modern" cognitive abilities had appeared in Africa by 75,000 years ago (d'Errico et al. 2005). During the next few years, the pre-UP origins of "symbolic" body ornamentation were further corroborated by the discovery of similar shell beads in Middle Palaeolithic layers of Israeli and North African sites occupied by anatomically modern humans (Vanhaeren et al. 2006; Bouzouggar et al. 2007; Bar-Yosef Mayer et al. 2009; d'Errico et al. 2009). ${ }^{1}$

1 It should be noted here that the "symbolic" use of body ornaments has been also associated with the Neanderthals occupying Europe at the time of the Middle Palaeolithic. Yet seeing how the available evidence is not as well received by the archaeological community, I decided to focus on the African shell beads associated with anatomically modern humans. Of course, this is not to say that an account of Neanderthal body ornamentation could not follow a line of reasoning much like the one outlined in this paper. 
But what exactly are the theoretical assumptions made on the basis of these archaeological discoveries? Having elsewhere overviewed the place of "symbols" and material signs in the debate on human origins (Iliopoulos and Malafouris in press), I shall now attempt to briefly summarize the common assumptions made regarding their nature, emergence, and evolution. This quick overview should set the scene for the move towards aesthetics, proposed in the next section.

Starting with the first of these three issues, it is important to note that prehistorians usually account for the nature of material "symbols" by employing a model based on the semantic and syntactic organization of language. The archaeological consensus seems to converge on the idea that shell beads are connected to what they stand for through arbitrary conventions, much like words, and that they are syntactically arranged to form beadworks which function much like propositions (e.g. d'Errico et al. 2005; Stiner 2014). This linguo-centric understanding of material culture is a logical corollary of the representational mechanism invoked in order to explain the emergence of artefacts. By assuming - what Ingold (2010) refers to as - a hylomorphic ${ }^{2}$ model of creation, scholars tend to consider the shell beads retrieved as the epiphenomenal products of "symbolically"-capable and by extension, "modern" human brains (e.g. Henshilwood and Dubreuil 2011; Cole 2015). This representationalist point of view is closely tied to an "internalist" conception of the mind, wherein cognition is located in a brainbound apparatus that processes "symbolic" representations constructed through the collection of input from the world, before externalizing them by way of deliberate behavior. In assuming a cognitivist take on cognition, archaeologists also assume a Neo-Darwinian approach to evolution, which treats biological and cultural evolution as parallel, yet distinct trajectories. By describing the evolution of culture in the adaptationist terms of natural selection, archaeologists essentially arrive at a conception of communicative artefacts, such as early body ornaments, as information technology that provides adaptive solutions to looming demographic problems stemming from increasing population sizes (e.g. Kuhn and Stiner 2007; Kuhn 2014; Stiner 2014).

As has been suggested though (Malafouris 2013; Iliopoulos 2016b; Iliopoulos and Malafouris in press), the theoretical assumptions made by the "symbolocentric" paradigm are not particularly helpful for the purposes of a discipline mainly preoccupied with material objects. To put it epigrammatically, adopting the analogy of material culture as language or text entails committing - what Lambros Malafouris (2013: 91) calls - the fallacy of the linguistic sign, because

2 The term hylomorphic comes from the Greek words hyle (matter) and morphe (form). 
these semiotic ontologies produce meaning in very different ways. Handling material culture with tools specifically designed to describe language leaves a large part of the material semiotic domain entirely unaccounted for (Knappett 2005: Chapter 5; Malafouris 2013: Chapter 5). Moreover, suggesting that form and meaning are predefined by an internal apparatus before being externalised into the world entails committing - what Malafouris (2013: 237) calls - the representational fallacy. Attributing cultural novelties to the representational mechanism of a prodigious inventive mind does not really explain how exactly they were conceived in the first place. The main reason that a representational approach falls short is because it assumes an "internalist" model of cognition that is not tailored towards accounting for most real-life cognitive tasks, which require humans to think through an embodied engagement with their physical environment (Malafouris 2013, chapter 4; Iliopoulos and Garofoli 2016). Prioritizing the neural apparatus over the material world also precludes one from taking the remarkable neuroplasticity of the human brain adequately into account. While the fact that the brain affects things and events is certainly irrefutable, the idea that "external" entities shape the way we come to think about them must also be taken into consideration. Otherwise, we are unavoidably bound to prioritise biological over cultural evolution - a neo-Darwinian idea that maintains an unhelpful dichotomy between the two. By taking as a given that these processes are unravelling in linear and deterministic paths of their own, we are ultimately precluded from seeing how they are intimately entwined dimensions of the same ontogenetic process (Ingold 2013; Malafouris 2013: Chapter 10).

In order to grant merit to matter for its role in the nature, emergence, and evolution of mind and culture, Malafouris (2013) has recently developed an evolutionary epistemology known as the Material Engagement Theory (MET). For the proponents of MET, we must strive to explain the origins of early body ornamentation by relying on a materially-sensitive and praxis-oriented set of theoretical dispositions (Malafouris 2008; Garofoli 2015; Iliopoulos 2016a). Succinctly put, the nature of material signs needs to be described through a pragmatic approach according to which the meaning of body ornaments is associated with situated instances of material engagement, because it is during, or better yet through these processes that shell beads become meaningful as objects. This brings us to the issue of their creation, which MET attributes to a process of discovery that takes place through the unique inclination of humans towards making. Explaining the emergence of form and meaning through practice requires opting for a hypostatic ${ }^{3}$ account, which attributes the development

3 The term hypostatic comes from the Greek words hypo (below) and statiko (causing to stand). 
of concepts to a process that Renfrew (2001: 129) dubbed substantialization. Based on the idea that material forms actually substantiate the meanings associated with them, we can explain adornment through a logic of improvisation wherein novelties are brought forth right then and there. Doing so entails assuming an "externalist" conception of the mind inspired by the embodied, embedded, enactive, and extended mind theories that are currently gaining traction in the philosophy of mind and cognitive science. In turn, recognizing that cognition extends beyond the limits of the braincase and even the body frees us from the need to explain the origins of mind and material culture by relying on a prodigious brain that had already evolved. By adopting a developmental and ontogenetic perspective on evolution, we are ultimately able to trace the long-term changes that brought forth material signification and symbolic cognition though a series of situated engagements between brains, bodies, and things.

\section{Aims: Moving towards aesthetics}

While the "symbolic" aspect of ornaments has evidently stirred much debate, their aesthetic dimension has received much less attention - mostly because the ornaments retrieved are generally associated with the "symbolic" communication of particular messages of adaptive significance. And even in the rare case that the possibility of an aesthetic meaning was considered, Henshilwood and Dubreuil (2011: 391) still invoked the same neurocognitive abilities required for "symbolism," on the basis that "good taste" is an abstract property that must have been conventionally linked to personal ornaments much like other concepts. Garofoli (2015) later resisted this "symbolocentric” explanation by positing that early body ornaments would have primarily been "iconic." ${ }^{4}$ From the vantage point of a Radical Enactive Cognitive Archaeology (RECA), their aesthetic appeal would have been directly perceived without having to resort to a theory dictating good taste.

This dissonance naturally raises some questions: Were aesthetic rules "symbolically"-guided, or directly perceived? And could there be a third possibility, wherein perception and conception are brought together in yielding a significative

4 Rather than establishing similarity between body ornaments and their wearers based on shared qualities, Garofoli (2015: 814) advances a definition of iconicity, according to which ornaments are iconic because they incite emotional responses by altering and "extending" the appearance of their wearers' bodies. 
form of art, otherwise seen as an artistic form of signification? In order to address these questions, we must delve into the cognitive and semiotic mechanisms that drove the creation of aesthetically-appealing ornaments. To this end, I shall be putting forth an approach that is best seen as a semiotic extension of the enactive framework that MET introduced to cognitive archaeology. Seeking to place the material dimensions of signification at the forefront of this framework, I have elsewhere outlined a pragmatic and enactive theory of cognitive semiotics that is suitably geared to trace the nature, emergence, and evolution of material signs (Iliopoulos 2016a, Iliopoulos 2016b).

The methodological part of the paper thus starts with an overview of this composite framework, which brings together a variety of compatible analytical tools, able to address many of the issues concerning prehistorians (Section 3). As I demonstrate, this theory of cognitive semiotics is able to define material signification, and establish the criteria for sign function (Subsection 3.1); to recognize non-symbolic forms of relevance, and identify different kinds of iconic and indexical signification (Subsection 3.2); and to illuminate the cognitive mechanism behind the emergence of material signification, as well as the semiotic scaffolding behind the evolution of symbolic narratives (Subsection 3.3).

After considering tools that can help us address these issues, I extend the cognitive semiotic theory into the realm of aesthetics (Section 4). In doing so, I plan on making the composite framework sufficiently capable of specifying the nature of aesthetic signs (Subsection 4.1), accounting for their emergence (Subsection 4.2), and tracing their evolution (Subsection 4.3).

Having set the necessary theoretical foundations, I then apply this composite framework to the case of early body ornamentation in an attempt to trace the co-development of aesthetic artefacts and cultural identity (Section 5). As the ethnographic record informs us, ornamentation and identity seem to have strong links. In her work on Northern Kenya, Williams (1987: 34) characteristically reports: "In Turkana, to be without ornament is to be without identity." To explain the connection between the two, I shall be proposing that thinking about the effects and affects of group-specific ornaments would have enabled early humans to conceive themselves as integral elements of - what the Lund conception of cultural semiotics (Sonesson 2016) would treat as - a prehistoric Ego-culture. Of course, such a realization could have only been made against the backdrop of so-called Alter- and Alius-cultures (Cabak Rédei 2007), as the prehistoric landscape would have been inhabited by social groups practicing different forms of ornamentation, as well as ones lacking it completely. From the perspective adopted in this paper, it was an aesthetically-founded Ego-culture that formed the basis for the signification of their wearers' cultural identity and by extension, their group affiliation. 
After applying the extended version of the cognitive semiotic framework to the case of early body ornamentation, I return to the question of whether aesthetic appreciation is "symbolically"-guided, perceptually-based, or something in-between (Section 6). In working towards an answer, I embark on an evaluation of the "symbolocentric" point of view, which, in emphasizing the importance of reflective thinking, seems to overlook the active role of the material world in shaping mind and culture (Subsection 6.1). RECA on the other hand, attempts to overcome overly mentalistic tendencies by advancing a narrative solidly grounded on the direct perception of affordances and embodied intentions, as these are revealed by orientation, posture, motion, gaze and expression. In doing so though, the radically enactive approach lacks in reflectivity, because it cannot really explain how certain artefacts can cue the cognizance of something that is not directly available but that everyone involved is aware of, and even more importantly, is aware of sharing. While I indubitably value the importance that the perception of dispositions has in shaping our aesthetic taste, I find it important to recognize that our aesthetic ideals are also shaped through the agentive effects of material signs mediating iconic, indexical, and symbolic meanings alike (Subsection 6.2).

I thus ultimately arrive at a middle ground of sorts (Section 7). Like Cappuccio and Shepherd (2013), I eventually opt for an approach that complements the reflectivity of the representational model with the reciprocity of the dispositional approach. Seeing how the aesthetic appeal of early body ornaments depends on their physical qualities as much as it depends on their significative meanings, the concluding section highlights the importance of focusing the long-term scope of evolutionary cognitive archaeology on the codevelopment of aesthetic ideals and conceptual ideas. I admit, of course, that working our way towards this conclusion will not be a quick and easy task. Taxing as it may be though, I hope that the path towards this end will prove to be one worth taking. On this note, it is time we get into the nitty-gritty details of our cognitive semiotic theory.

\section{Theoretical framework: Composing a pragmatic and enactive theory of cognitive semiotics}

The composite framework at hand is mainly based on the synergistic fusion of two theoretical tenets that emphasize the ontological primacy of process and action: pragmatism (from the Greek noun $\pi \rho \tilde{\alpha} y \mu \alpha$ \{pragma\}, "act”) and enactivism. Broadly speaking, pragmatism is the philosophical tradition that aims to elucidate 
the relation between the ideational and the material by bringing human practice at the forefront of philosophical inquiry, while enactivism is a theory of cognition that attributes the formation of knowledge to the probing of the environment through the skillful manipulation of things. The variants of these strands employed here specifically include Peirce's pragmatic theory and Malafouris' enactive evolutionary epistemology. While the writings of the former provide us with a semiotic typology that helps us accurately describe the nature of past material signs, the work of the latter offers us a cognitive archaeological account of their situated emergence and evolution. It should be noted of course that, while the toolkit of our analytical framework is mainly grounded in the theories of Peirce and Malafouris, it also incorporates epistemic tools borrowed from other scholars, since their implementation helps illuminate the workings of material signification. The theoretical postulates of Göran Sonesson have for instance been integrated in order to better describe the nature of material signs. Yet inspiration has also been drawn from the work of Jesper Hoffmeyer (2007, 2014a, 2014b), who attributes the emergence and evolution of signs to a process of semiotic scaffolding. Though Hoffmeyer subscribes to the biosemiotic school of thought, his work has made it abundantly clear that the concept of semiotic scaffolding can also be applied to cultural contexts, much like the ones we are interested in here. There is thus no cause of concern regarding its theoretical compatibility with the other facets of the cognitive semiotic toolkit presented in this section.

Before delving into its various facets though, we must first point out that the composite theory of cognitive semiotics outlined in what follows is open to further expansion through the addition of other compatible tools, or the modification, or even the replacement of existing ones. To this extent, what follows should be seen as a working version of a cognitive semiotic endeavour still in progress. That said, let us for now focus on how the current form of the toolkit helps address a series of interrelated questions that arise when studying past material signs:

3.1 What exactly are material signs? In other words, how can material signification be defined? And which criteria does a human sign need to fulfil in order to really count as such?

3.2 Which forms do material signs take? Do they only occur as purely arbitrary conventions, or can they appear as physically-grounded modes of signification? And if the latter happens to be the case, are there different kinds of such signs?

3.3 How do material signs develop in place and over time? Firstly, what is the cognitive mechanism behind the emergence of material signification right then and there? And secondly, how does the development of signs scaffold over time the evolution of symbolic practices and narratives such as rituals? 


\subsection{Defining material signification, and establishing criteria for sign function}

Before delving into the specifics of material signification, a distinction between three states of meaningful being is in order - namely that between Firstness, Secondness, and Thirdness (CP 1.24-1.26). ${ }^{5}$ According to Peirce's famous doctrine of categories, Firsts are qualitative possibilities that exist regardless of anything else, Seconds are brute facts that exist as an actual relation to something else, and Thirds are predictive rules that exist in relation to this relation. Though, it is perhaps best for the purposes of our social analysis if we conceptualise Firsts as fleeting appearances, Seconds as manifested reactions to these appearances, and Thirds as reflective observations of these reactions to the appearances (Sonesson 2013a). From Sonesson's point of view, Peirce's triadic relations let us account for a phenomenological process that involves: the first appearance of something to consciousness, its emergence as something that can be intentionally directed towards, and this emergence itself becoming the theme of consciousness. Thusly seen, the three phenomenological categories can help us describe the conscious experience of material culture, as is for instance exemplified by the fleeting appearance of valuable ornamentation (First), which is physically embodied when actualised in the reaction that early humans would have had towards valuable ornaments (Second), thus inciting and shaping the general observation according to which they would have predicted that a thought about valuable ornamentation will be generated when valuable ornaments are encountered in the future (Third). ${ }^{6}$

Following the triadic logic of his categories of being, Peirce's semiotic theory treats semiosis as a triadic process through which a Sign or Representamen (First) comes to stand for something else, its Object (Second), in producing a feeling, a reaction, or an idea called an Interpretant (Third). It is

5 Adhering to scholarly tradition, I cite Peirce's work as CP (followed by volume and paragraph number in The Collected Papers of Charles Sanders Peirce).

6 Besides addressing the sensitivities of an archaeologically-inclined framework towards material culture, Peirce's triadic logic can also help us attune our cognitive semiotic theory to the social relations between a person and another person or even a nonperson. To put it in Sonesson's (2000) terms, it helps us relate the Ego to the Alter and the Alius in two important ways. For one, an Ego can be seen as a Second relating to an Alter, treated in this case as a First. The relationship between the two is mediated in the form of empathy, which thereby acts as a Third. In another scenario, it is the Ego that can be seen as a Third that is observing the relationship between an Alter, acting in this instance as a Second, and an Alius, which assumes the role of a First. 
therefore important to acknowledge the distinction between an emotional (First), an energetic (Second), and a logical (Third) Interpretant (CP 5.4755.476). It is also important to note here that the Sign does not represent its Object in a reflective sort of way, as Peirce had associated the Sign with a mediating role. The reason that the representational function of the sign is best seen as a mediational affair is that it comes to stand for something in some respect or capacity - a relation of relevance that Peirce called the ground of the sign. The recurring interpretation of the semiotic ground via the Sign is what is essentially entailed in the formation of habits - that is, in the motivated dispositions to act in a certain way under certain circumstances, which are essentially beliefs when deliberate or self-controlled (CP 5.480). It thus follows that a belief concerning the meaning of an artefact such as a beadwork could be seen as a deliberate or self-controlled habit of interpretation (Third), formed by appreciating the relevance between the shell beads and what they stand for (Second), a relation itself embodying a quality such as "value" (First). To this extent, the material signs studied by archaeologists are best seen as objects associated with significative meanings due to their involvement in actual relations of relevance concerning their possible qualities. Given that a material sign relies on the simultaneous interplay of possibilities, manifestations, and laws, material signification seems to escape the mental and physical confines set by idealists and realists respectively. From the perspective adopted here, the material sign is best seen as a conflation of potential qualities (Firstness), particular facts (Secondness), and general rules (Thirdness). By recognizing the distinction between potentiality, actuality, and necessity, we thus arrive to the understanding that what the archaeological record provides us with is a glimpse of possible qualities, embodied by actual perceptual contexts, experienced by past peoples as regular patterns.

Yet we have no way of knowing what sort of rules they would have grasped through (repeated) exposure to and experience of primordial perceptual facts. Could they have been of a significative, rather than of a simply perceptual nature? From the perspective assumed here, grasping a relation of relevance, whether be it an iconic or indexical ground, is not enough to justify speaking of a truly significative function. According to Sonesson (2006, 2007, 2010, 2012), to speak about sign function proper, the thing signifying and the thing signified must (among other things) be doubly differentiated, in that the sign's Expression (i. e. the Sign or Representamen) and its Content (i. e. its Object and the respective Interpretant) must not go over into each other in time and/or space, and must be perceived to be of different nature. To thus say that artefacts such as the Blombos beads (the Expression) had been used as material signs for "value" (the Content), is to suggest that they did not overlap in 
time and/or space; after all, the beadwork is in the here and now, while its "value" is spatiotemporally extended. They should have also been perceived to be of different nature given that the beadwork is material, whereas "value" is mental. Yet in order to be conceived as parts of a sign relation, Sonesson (2006, 2007, 2010, 2012) notes that the two relevant things must also be doubly asymmetric, in that it is the latter that is brought to the interpreter's attention despite the fact that the former is more readily accessible. In the case of early body ornamentation, "value" should have been the focal point of the interpretive action, despite the fact that it is the beadwork that would have come to one's immediate attention. At this point, the two things constituting the semiotic relation had been subjectively differentiated, in that the Expression of the sign would have been directly given and nonthematic, whereas its Content would have only been indirectly present and thematic. It should thus follow that the interpretation of early body ornaments as material signs (in the strict sense of the term) had involved the capacity to subjectively differentiate between the Expression of the sign (i. e. the actual artefact) and its Content (i. e. what it stands for) - besides of course an appreciation of the adornments' relevance to their own "value" or to their wearer's "wealth," to name but a couple of examples (Iliopoulos 2016a).

From the long-term archaeological perspective of our evolutionary epistemology, cultural forms of signification such as ornamentation became truly established when humans eventually came to appreciate the mental strategies that it involves. As I see it, speaking about deliberate sign use through body ornamentation entails metacognition on the part of the makers and wearers of the artefacts. This is of course not to imply that metacognition would have been a pre-acquired capacity employed as a matter of course in the case of ornamental signification. Quite the opposite, in fact, as it is suggested here that thinking about thinking, as a capacity itself, would have developed in concert with cultural practices such as ornamentation, which would have given humans ample opportunity to think about the mental strategies involved in signification. What were seen as informative signs would have had to be in a state of constant re-evaluation through the negotiation of new perceptual cues and prior experience. As one would expect, this ongoing process of habit change must have challenged the beliefs of early humans, forcing them to become aware of their interpretive capacity and its limits. It is not hard to see then why the development of meta-representational thinking would have become instrumental for the conscious and deliberate manipulation of signs that made human culture and symbolic systems so unique. 


\subsection{Recognizing non-symbolic forms of relevance, and identifying different kinds of iconic and indexical signification}

Given that sign function is underpinned by relations of relevance, it would be useful here to make a distinction between the different ways that Signs are connected with their Objects. As we have already seen in the introduction of this paper, most prehistorians treat all the connections between material signs and what they stand for as inherently "symbolic," on the basis of the idea that their arbitrary meanings are the epiphenomenal products of "symbolic" human cognition. Against this general tendency, a small number of scholars has drawn attention to the role of the physical world in supporting the iconic and indexical meanings of ancient artefacts (e.g. Garofoli 2015; Noble and Davidson 1996; Deacon 1997; Rossano 2010). By definition, things that are iconically related share certain qualities that inhere in them independently of the sign relation (Sonesson 2006: 165), while things that are indexically related are actually connected with each other through contiguity or factorality (i. e. a part/whole relation; Sonesson 2006: 174-175). Symbolic signs, on the other hand, are linked to what they stand for neither via means of similarity, nor by way of contiguity or factorality. Their sign function is instead inextricably tied to a semiotic ground that is purely arbitrary, because there is nothing in the Sign and its Object that explains the sign relation that produced a principle of relevance between them (Sonesson 2006: 172). To distinguish this narrower definition of symbolism from "symbol” as a synonym for a "sign” deliberately constructed by an inventive mind that has mastered language, the quotation marks are dropped when dealing with the semiotic (rather than the archaeological) notion of the symbol. I shall be doing this, for instance, when considering symbols in tandem with icons and indices - categories of signification overlooked as a result of an excessive preoccupation with the linguistic connotations of prehistoric objects.

That said, it is important to note here that the three sign types described by Peirce are not mutually exclusive. Early body ornaments might have been seen, for example, as signs of "value" due to grounds of similarity, as signs of "wealth" due to grounds of contiguity, and as signs of "status" due to purely arbitrary grounds - although there is no way of knowing for sure (Iliopoulos 2016a). It should nevertheless be safe to say that when these objects were eventually conceived as significative, their meanings must have primarily relied on iconic and indexical relevance. It would therefore be useful to delve, in this subsection, deeper into each of these kinds of signification, so as to bring their finer intricacies to the forefront. Making a distinction, in particular, between 
different kinds of icons and indices is important because it helps us overcome some traditional misconceptions about icons always being associated with readily perceived similarities, and indices only describing states of affairs. On this note, let us start with the iconic, before proceeding to the indexical varieties of signification:

According to Sonesson (2010, 2013b, 2013c), icons can be distinguished into primary and secondary types, depending on whether their iconic relevance can be readily appreciated, or prior knowledge is required in order to glean the qualities they share with what they stand for. In the former case, the perception of similarity between two things is at least partly the reason for taking one of them to stand for the other. For instance, the figurative representations found on prehistoric cave walls can be seen as primary icons, because they would have come to function as signs on the basis of their similarity to actual things or events (Iliopoulos 2016b: 116). In the case of secondary icons however, knowing that one thing stands for another in a system of interpretation is at least a partial reason for perceiving their similarity. Secondary icons are objects that, while normally used for other purposes, have come to stand for themselves, for some of their properties, or for the class to which they belong, in particular situations and according to specific conventions. Ochre pigments, for instance, might have normally been used for practical purposes until they came to signify value by standing for themselves, their properties (e.g. rarity), or the class of (rare) objects they belong to, because interpreting them as signs of "value" requires being familiar with the cultural context in which they are deemed valuable (Iliopoulos 2016a: 263). As Renfrew (2001: 134) points out, the concept of "value" is a social idea because it implies some measure of shared value as established between individuals. Having thus recognized that iconic semiosis is not limited to readily perceptible meanings since it can involve significative conventions, it is now due time that we turn to the other kind of physicallygrounded signification.

To really appreciate the indexical function of material signs, let us consider a distinction between - what Sonesson (2006) - calls abductive and performative signs. In the case of the former, pre-existing grounds of contiguity and/or factorality between two things enabled humans to abductively acquire the cultural knowledge required to appreciate that one of them can stand for the other. Such indices thus come to describe states of affairs, as exemplified in the case where a beadwork comes to reference one or more qualities of its wearer. In the case of the latter kind of indexical signification however, the contiguity or factorality between two things is created at the moment that the sign is given. Spontaneous performative indices do not necessarily rely on prior knowledge. Such indices create states of affairs, as seen in an ethnographic example from 
Janowski's (1998) research on the Kelabit of Sarawak, East Malaysia, where the potential to be "good" is inherited via the acquisition of beads whose value depends on who owned them in the past. From a semiotic point of view, the body ornaments confer meaning on their wearer when being worn, because they effectively establish an indexical ground between the two of them. Hence, if prehistoric shell beads are to be viewed as indexical, we must move past the tendency to reduce the function of material signs to reference alone, and recognize that they can also be performative. In fact, for a detailed understanding of how the performative and abductive aspects of ornamental signs unfold, we must also recognize that these kinds of indexical function are not mutually exclusive. The dual operation of indices can be seen in Carey's (1998) ethnographic work where ornamental beads were deemed to function concurrently in both abductive and performative ways. As she notes: "The insignia worn by royalty and the priesthood in Nigeria, Cameroon and Zair show clearly how an important man's status is marked [i. e. the abductive function] and enhanced [i. e. the performative function] by his official beadwork" (Carey 1998: 89, brackets not in original). By extension, when prehistoric body ornaments would have come to signify properties of their wearer, they would have done so by both referencing and conferring them at the same time (Iliopoulos 2016a).

\subsection{Illuminating the cognitive mechanism behind the emergence of material signification, and the semiotic scaffolding behind the development of symbolic narratives}

In order to examine the creation of material signs from a cognitive point of view, the theoretical framework outlined here opts for the hypothesis of enactive signification. Advanced by Malafouris (2013: chapter 5) within the context of the Material Engagement Theory, this working hypothesis accounts for the co-emergence of concepts and their significative materialization by employing Hutchins' (2005) materialist interpretation of Fauconnier and Turner's (2002) conceptual blending theory. According to the theory of conceptual blending, direct implicit ontological correspondences are established between different experiential domains by way of integrative cognitive projections that project them into a third space, the blend. As Hutchins (2005) points out, material structures can be directly projected in a conceptual blend, stabilizing and anchoring in effect the conceptual to the material. According to this logic, ochre pigments and beadworks could have functioned as the material anchor required for processes of conceptual blending that brought forth meanings such as the iconically-grounded understanding of "value" or the indexically-grounded comprehension of "wealth"; 
and after a while, the accumulation of physically founded meanings in the same sign vehicle could have brought forth purely arbitrary concepts such as "status," since properties not implicated in any of the original domains can also emerge in a blended space (Iliopoulos 2016a: 266). Given that there is nothing in the Sign (i. e. the ornament) and its Object (its wearer's "status") that explains the sign relation that produced a principle of relevance between them, we can at this point speak of a truly symbolic kind of material signification.

Yet in order to appreciate how physically grounded modes of signification scaffolded the development of symbolic material culture, we need a typology that is not only descriptive, in that it must accurately describe the nature of signs, but also explanatory, in that it can sufficiently explain how the different kinds interrelate with one another (Iliopoulos 2016b). For a more precise picture of the semiotic nature of the sign, we can simply return to Peirce and his classificatory typology.

While the Icon-Index-Symbol triptych serves us well in identifying the kind of relation between the sign and what it stands for, it does not help us account for the relations between the sign and itself, or the relations between the sign and its meaning. In describing the kinds of Sign-Sign relations, Peirce made a distinction between signs as qualitative possibilities, called Qualisigns (CP 2.244), signs as actual things/events, called Sinsigns (CP 2.245), and signs as general rules, called Legisigns (CP 2.246). Moreover, in accounting for the kinds of Sign-Interpretant relation, he distinguished between signs that denote the thing signified in a way that is neither true nor false, called Rhemes (CP 2.250), signs that provide information about it in a way that is either true or false, called Dicent Signs (CP 2.251), and signs that dictate it in a way that tends towards its own truth, called Arguments (CP 2.252).

By combining the Icon-Index-Symbol triad with the Qualisign-SinsignLegisign and Rheme-Dicent-Argument triptychs, Peirce came up with a typology of signification that allows us to examine the meaningful spectrum in greater detail than that allowed by the first distinction alone. While the combination of the three trichotomies can produce a total of twenty-seven possible sign combinations, only ten of them are underpinned by logic. Unfortunately, space restrictions preclude us from delving into the finer intricacies of these classes. That said, it might be useful to list the terms epigrammatically, including as parenthesized elements redundancies omitted in Peirce's original account, for clarity purposes. ${ }^{7}$ To give some indication of what the ten signs may be about, Peirce's semiotic

7 These redundancies result from the fact that a Qualisign can only be an Icon and a Rheme, an Icon can only be a Rheme, a Dicent Sinsign can only be an Index, a Symbol can only be a Legisign, and an Argument can only be a Symbolic Legisign. 
jargon has been "translated" into somewhat more palpable terms, which are then demonstrated through a characteristic example given by Peirce himself:

1. The (Rhematic Iconic) Qualisign is a qualitative possibility, such as the feeling of red (CP 2.254).

2. The (Rhematic) Iconic Sinsign is a denotative iconic instantiation, such as an individual diagram (CP 2.255).

3. The Rhematic Indexical Sinsign is a denotative indexical instantiation, such as a spontaneous cry (CP 2.256).

4. The Dicent(-ic) (Indexical) Sinsign is an informative indexical instantiation, such as a weathervane (CP 2.257).

5. The (Rhematic) Iconic Legisign is a denotative iconic rule, such as a diagram (CP 2.258).

6. The Rhematic Indexical Legisign is a denotative indexical rule, such as a demonstrative pronoun (CP 2.259).

7. The Dicent(-ic) Indexical Legisign is an informative indexical rule, such as a street cry (CP 2.260).

8. The Rhematic Symbol(-ic Legisign) is a denotative symbolic rule, such as a common noun (CP 2.261).

9. The Dicent(-ic) Symbol(-ic Legisign) is an informative symbolic rule, such as an ordinary proposition (CP 2.262).

10. And finally the Argument(-ative Symbolic Legisign) is a truth-tending symbolic rule, such as a syllogism (CP 2.263).

Applying this tenfold typology to early body ornamentation allows us to appreciate that the meanings associated with prehistoric shell beads may range from qualitative possibilities (e.g. rarity), to denotative iconic instantiations (e.g. appreciating that the rare shell beads encountered signify "value") and informative indexical instantiations (e. g. understanding that they signify their wearer's "wealth"), to propositions (e. g. thinking that such rare shell beads signify their wearer's "status"), and ultimately full-blown syllogisms (e.g. thinking through ornament-based rituals). Interestingly, Peirce's typology does more than allowing us to describe various types of signification; it also helps us acknowledge their relations to one another, thus letting us appreciate the interdependence of different kinds of meaning. For instance, ornament-based ritualistic narratives depend on symbolic propositions about the "status" of the ornament's wearer, while the indexical connection between beads and the wearer's "wealth" is grounded in the signification of "value," a concept embodying (in this case) the quality of rarity (among others) (Iliopoulos 2016a).

From an evolutionary standpoint, it would make sense to expect icons and indices to have emerged first, if only because the underlying grounds of 
similarity, contiguity, and factorality fall subject to the auspices of perception (Iliopoulos 2016a, Iliopoulos 2016b). It seems reasonable then to suggest that the perception of iconic and indexical forms of relevance would have preceded the conception of iconic and indexical signs, in the strict sense of the term. Only after humans had understood that an artefact can stand for another object, could they have realized that the semiotic connection might well have been entirely arbitrary. To add to this, only once iconic, indexical, and symbolic forms of Rhematic and Dicentic signification had appeared, could Arguments such as rituals form. What would have come last (as far as the evolution of material culture is concerned) are the practices that were composed entirely of propositions, linked through one-to-one associations much in the way that connected premises lead to the conclusion of a syllogism. As I see it, cultural syllogisms such as those dictating rituals would have emerged only after a number of denotative and informative icons and indices had been consolidated, at least to an extent. Seeing how the semiogenetic mechanism entailed in material signification focused the energy flow or behavior of the cultural system to a rigidly limited repertoire of semiotic possibilities (e.g. these rather than those symbolic narratives), I have elsewhere proposed that the evolution of material culture was catalyzed by processes of - what Hoffmeyer (2007, 2014a, 2014b) has called - semiotic scaffolding (Iliopoulos 2016a, Iliopoulos 2016b). During their ascent towards more elaborate forms of semiosis, humans transitioned from the perception of relevance to its conception as significative, and from the conception of iconic and indexical meanings to the conception of symbolic propositions and narratives. That said, it is also important to recognize that, once higher-order forms of significative material culture had been attained through the support of lower-order forms of signification, such syllogisms would have in turn dictated the form and use of the artefacts involved. Essentially then, the connections between the different layers of meaning described by Peirce are best seen as bidirectional.

\section{Theoretical extension: Integrating aesthetics into our composite framework}

While "symbolic" constructs may at first seem to generate only thoughts, it is important to acknowledge that they also function at a much more "primal" or "carnal" level, for they also incite feelings and reactions. As we have already seen, Interpretants are not always logical (Thirds); they can also be energetic, when physical/mental reactions are involved (Seconds), or emotional, if feelings 
are elicited (Firsts). In fact, given that the same kind of material culture may involve the generation of more than a single type of Interpretant, it is important to acknowledge that the logical processes associated with "symbolism" are closely tied to the aesthetic appreciation of material forms. This interdependence can be clearly seen in the ethnographic record on the Hageners' rituals, where "aesthetic judgements are in fact closely related to the symbolism of the decorations" (Strathern and Strathern 1971: 11). Another illustrative case from Papua New Guinea comes from the Trobrianders, who adorn their infants because "shell decorations add a fundamental degree of power to the baby's potential social beauty" (Weiner 1988: 59). Most notably though they decorate their canoe board-prows in order to overawe their overseas Kula partners. According to Gell (1992: 44), such a technology of enchantment "is supposed to dazzle the beholder and weaken his grip on himself." The Trobrianders would thus utilize decorations attesting to their magical powers as a means of inducing specific psychological responses. In doing so, they were able to extract more valuable shells or necklaces than their Kula partners would be inclined to offer. In light of these ethnographic findings, it would not be unreasonable to suggest that prehistoric forms of adornment could have also had similar effects. Of course, this is not to be taken as a proposal that early body ornaments had been deliberately created in order to serve such purposes; only that they would have come to function as feeling-inducing art through situated instances of material engagement.

In order to be able to examine how such an aesthetically meaningful form of material culture could have come to be, we need to attune our theoretical framework to the domain of aesthetics. Given the cognitive semiotic scope of our paper, it would probably be wise to steer clear of debates taking place in art theory and evolutionary aesthetics. While much has already been said about art and its origins, we opt here for the theories defended by Peirce and Malafouris. Conveniently so, the pragmatic and enactive takes on aesthetics they have respectively advanced, fit right in place with the theoretical tools of theirs outlined in the previous section. Essentially then, I will be attempting to extend our composite framework so that it can also address the following questions:

4.1 What is the nature of artistic material signs? In other words, how can aesthetically meaningful forms of material signification be described from a semiotic point of view?

4.2 How do artistic material signs emerge right then and there? To be more specific, what is the relation between aesthetically meaningful material signs and the creative agency of their makers?

4.3 How did artistic material signs evolve in the human lineage? To be exact, what are the evolutionary mechanisms that drove the appearance of aesthetically meaningful material signs? 


\subsection{Describing the nature of artistic signs}

A suitable point of departure for extending our theoretical framework into the realm of aesthetics and art would be defining what exactly it is we mean when talking about these notions. To this end, let us turn to the pragmatic theory of Peirce, as interpreted by the philosopher and semiotician Martin Lefebvre (2007). For Peirce, aesthetics is not just about the appreciation of art and the beautiful, but about the formation of ends or ideals. It thus seems necessary that, before focusing on artistic ideals, we first appreciate how ideals are generally formed. We must therefore start from the Peircean quality of feeling - the lowest sign class in the tenfold typology (i. e. the Rhematic Iconic Qualisign). According to Lefebvre, perceiving a quality of feeling makes its regularization more likely. Once regularized, qualities of feeling are associated with other qualities of feeling, therefore forming a general idea. Granted that Reason is that which "always must be in a state of incipiency, of growth" (CP 1.615), an idea that spreads, grows, and incites other feelings is deemed to be reasonable. It thus adheres to the supreme ideal, for "the only thing that is admirable in itself, independently of any reason, is reason itself" (Lefebvre 2007: 324). Given the fact that the aforementioned idea is admirable in itself, it becomes habitualized even before the consequences of adopting it are inductively evaluated. Because it grows through habit, Peirce appropriately termed it habit of feeling (CP 1.574). Such habits are hierarchized into ideals, against which future ideas are evaluated. Occasionally, these new ideas challenge and even replace ones previously had. Habits of feeling, and thus ideals, are consequently subject to change elicited by chance, spontaneity, and creativity. On the other hand, the more they grow and consolidate, the more qualities of feeling they attract. It is this constant incipiency of Reason that we find admirable in the ideals involved in feeling, and therefore art.

In light of Peirce's Reason-governed aesthetics, the creation of art is about reproducing perceived qualities of feeling on the basis of habitually established ideals (Lefebvre 2007). It is to this extent then, that artists are preoccupied with the fulfilment of their ideals. According to Peirce, works of art incite "a consciousness belonging to the category of Representation, though representing something in the Category of Quality of Feeling” (CP 5.113). This means that, despite representing at the conceptual level of Thirdness, works of art are in fact experienced as feelings, which are Firsts. While this may initially seem paradoxical, it can be explained by reminding ourselves that iconicity pertains to the inherent qualities of things. Upon this realization, Lefebvre (2007: 337, emphasis in original) noted that, in speaking about the aesthetic experience of art, Peirce is essentially referring to "the contemplation of signhood (i.e. the quality of a sign 
qua sign) iconically standing for itself." As he saw it, works of art essentially allow us to appreciate how well they stand for themselves. It is this quality of a sign qua sign that makes art attractive, because it enables Reason to contemplate itself by way of mind (Thirdness). As Lefebvre (2007: 340, emphasis in original) puts it: "To develop, cultivate, and nourish the habit of interpreting works of art may/ ... /appear to be nothing short of cultivating a taste for signs." By contemplating their ability to use and interpret signs, humans are therefore able to embody the habits of feeling incited by the iconic nature of artworks in habits of action and thought. From this pragmatic point of view, it can be said that the habitual interpretation of the aforementioned canoe board-prows as signs to present the Trobrianders with valuable shells or necklaces, is a habit of thought that is actually founded upon an aesthetic ideal or habit of feeling mediated by decorative sign vehicles.

\subsection{Accounting for the emergence of artistic signs}

From the enactive perspective assumed in this paper, appreciating the situated emergence of aesthetically meaningful signs and their respective ideals requires that we turn to the closely connected notion of agency - that is, the ability to bring about changes in the world. As anthropological work has already shown, decorated canoe board-prows are used for the purpose of mediating the agency of their makers (Gell 1992, Gell 1998). What I would like to point out here though is that, while it is certainly important to acknowledge that a thing can have agency as an aesthetic object (Gell 1998), it is also imperative to recognize that " $a$ thing can become an aesthetic object because it has agency" (Malafouris 2011b: 126, emphasis in original). Appreciating the intricate dynamics between effect and affect essentially requires attending to - what Malafouris calls - the aesthetic of agency. From MET's point of view, this means attending to the meanings experienced through the process of material engagement. Malafouris (2013) draws upon enactivism, a recent theory of cognition that favors the ontological primacy of action over the brain, and whose proponents treat the mind as the emergent product of skilled sensorimotor engagement within our physical world (O’Regan and Noë 2001). According to the sensorimotor variety of enactivism, it is through our active exploration of the environment that we come to experience various ways of thinking. In fact, recent work on emotion has revealed that it too is actually grounded in situated embodied action (Colombetti and Thompson 2008; Slaby 2014; Xenakis and Arnellos 2015), and according to some scholars it even extends into the world beyond the body (Stephan et al. 2013; Krueger 2014; Carter et al. 2016). Seen through the lens of enactive cognitive science, the 
feelings associated with art are not only induced, but constitutively shaped by and through the creative activities humans and things engage in (Manzotti 2011; Penny 2017; March 2019). If we are to appreciate the production of aesthetically meaningful material culture through - what Malafouris (2011b: 131) calls enactive discovery, we must thus strive to illuminate how aesthetic processes of constitutive interaction between human and non-human agents unfold in particular ecological contexts.

To this end, we must turn to MET's hypothesis of material agency, according to which agency is the emergent product of situated activity (Malafouris 2013, chapter 6). As Malafouris sees it, if we are to accept that agency is about causal events in the physical world, rather than about representational events in our mental world, we must speak of intention-in-action; for he suggests that "[i]n the case of 'prior intention' no such correlation [between intentionality and agency] can be made before this intention becomes realized in the world-that is, before it meets its relevant condition of satisfaction" (Malafouris 2013: 139). Whether such a condition can be met or not depends on the pertinent affordance (Gibson 1979). Consider this: whether or not my intent to drink something in particular can be agentively manifested depends on whether my interaction with a specific object affords drinking. It should follow from this ecological approach to perception that intentionality and affordance are not properties of humans and things respectively, but constitutively entwined products of our engagement with the physical world. The proximity for instance between human bodies and shell beads affords an interpretation that is closely coupled with the intention to actually participate in an ornamental culture, such as the one guiding Kula partnerships. Of course, this should not be taken to suggest that humans and things are ontological equivalents with regard to agency, since humans possess a "sense" or an "experience" of agency - which is why Malafouris (2013: 215) notes that "it is not causality but consciousness that differentiates the human sense of agency from agency proper." It is therefore important that we decouple the experience of agency from the act of bringing about change in the world, if we are to understand intentionality and affordance as the emergent properties of material engagement. That said, it is still interesting to acknowledge that our sense of agency is incited and shaped by the causal effects we have on things, as well as the effects they have on us.

Seen from a semiotic point of view, the causality emerging in agentive relations between humans and things is - what Hoffmeyer (2007) calls - semiotic causality, because the causation of change takes place under the guidance of interpretation. To understand how meaning-making is involved in the production of effects, it might be helpful to consider a situated semiotic approach to material agency. In a semiotic analysis of pottery-based agentive networks, 
Watts (2008) points out that clay sign vehicles are what mediate contact between what they stand for and their cultural meanings. As far as material agency is concerned then, "one of the more substantive implications of the Peircean semeiotic is that people and things, including their interests, are conjoined through the principle of semeiotic mediation" (Watts 2008: 204). Keeping this point in mind allows us to shed new light on the issue of eliciting and shaping affects through the practical effects of the material world. In order to appreciate the fundamental role of semiosis in the aesthetic of agency, we must acknowledge that agentive objects, seen here as semiotic Objects, tend to force physical connections with their Signs, which produce emotional Interpretants when sensed. As would be expected, repeated experience of such brute facts leads to the formation of habits of feeling and by extension, aesthetic ideals. Applying these theoretical insights to the case of the decorated canoe board-prows allows us to appreciate that the feelings experienced by the Kula partners were emotional Interpretants guided by habits of feeling and aesthetic ideals that had been established through the repeated visits of the Trobrianders. It is therefore evident that the Trobrianders deliberately incited such monadic Interpretants (in concert with the triadic Interpretants involved in the interpretation of symbolism), in order to tap deeper into the psyche of others and therefore reap greater social benefits. Essentially, this catholicity of lived meaning is what Valsiner (2016: 193) calls aesthetic hyper-generalization - that is, an "explosion" of precise meaning that covers the whole subjective and intersubjective field by feeling. In the Trobrianders' case, the perceptual detection of an ornament and its carvings or color for instance ("carved and colourful canoe board-prows") leads to aesthetic generalizations ("beautiful ornaments") which seem to involve hyper-generalized meanings (“how beautiful!”).

\subsection{Tracing the evolution of artistic signs}

From the perspective of MET, evolution is best examined through a postgenomic model known as Niche Construction Theory (NCT). According to this ecologically-oriented take on evolutionary biology, organisms transform the environments they pass on to subsequent generations, effectively altering their developmental niches and by extension influencing the selection pressures exerted on them (Odling-Smee et al. 2003; see Laland et al. 2016 for a recent review). Humans in particular, have shifted the focus of natural selection from the organism alone to the organism in its epistemic niche, because the social and technological environments they create facilitate the learning process for the descendants that inherit them. From the vantage point of NCT, human 
evolution could then be considered as a process of cumulative epistemic engineering both leading to and driven by an increasing propensity for social learning (Sterelny 2012).

That said, it is also important to recognize that the activity of human beings is responsible for structuring not only their epistemic, but also their affective environments. Slaby (2014: 44, emphasis in original) recently touched upon "a kind of emotional niche construction," which allows us to experience a greater number and variety of emotions than we would have otherwise been capable of. Along similar lines, Menary (2014) introduced the term aesthetic niche to describe stable aesthetic artefacts, practices, and practitioners, the inheriting of which scaffolds and shapes the aesthetic development of neonates. As he suggests, growing up with this kind of cultural capital affects the redeployment of neural circuitry adapted to non-aesthetic functions (Menary 2014: 475). A developmental line of reasoning is also followed by Portera (2016: 45), who draws attention to the fact that our aesthetic approach to the world is shaped by - what she calls - an aesthetic inheritance from our parents and forebears. It should thus follow that aesthetic behaviors need not have evolved as specific adaptations; they can rather be seen as learned propensities afforded by our remarkably plastic brains.

This move away from the adaptationist tendencies of neo-Darwinism finds the evolutionary epistemology defended by MET much in agreement. From the perspective assumed here, niche construction is a heuristic that can shed much light on the evolution of aesthetic practices, if integrated with an enactivist take on cognition and creativity. Seeking to grant some merit to materiality for the role it played in human origins, Malafouris (2015) blends niche construction with the Bergsonian notion of creative evolution (Bergson 1998 [1911]). As he points out: "Human beings evolve by creating material things and assemblages which scaffold the ecology of our minds and shape the boundaries of our thinking" (Malafouris 2016: 290). While the important role of natural selection in evolution is not to be denied, creative material engagement must also be recognized as a catalytic driver of diachronic change. This is why MET directs its attention to the creative ways in which plastic minds and things have been integrated at various places and times. Seeing how the alterability that is natural to the sapient mind is a distinctly human feature, Malafouris (2010, 2013, 2015) calls us to focus on the plasticity of plasticity - otherwise referred to as metaplasticity.

According to the evolutionary account sketched in MET, the metaplastic phenomenon taking place during the artistic process, when brain, body, and raw material become one, must have presented the mind with the opportunity to recognize the different practical effects that changes in process have on its form. The wide variety of materials early humans appear to have engaged with, as well 
as the different ways in which they seem to have done so, must have provided them with plenty of affordances to start thinking about thinking. Becoming increasingly adept at forming and manipulating meta-representations is what ultimately led to the metacognitive abilities that made human minds so unique. One of these capacities is especially pertinent to the aesthetically-oriented scope of our framework, as it relates to thinking or feeling about feelings. By exercising this powerful variety of creative awareness, humans would have been able to develop - what March (2019: 4) calls - meta-emotion. The deliberate and methodic use of the aforementioned board-prows should stand as clear evidence of the Trobrianders having come to engage in a cultural practice that was established through the development of meta-emotional thoughts.

It is the prehistoric origins of precisely such meta-emotional thinking that we want to explore in this paper, so as to highlight its role in the development of ideas about group identity. Doing so, should allow us to learn something about the interplay between perceptual and conceptual forms of meaning. On this note, and having considered the theoretical framework to be used, it is now due time to delve into the case of early body ornamentation.

\section{Case study: Tracing how the aesthetic appreciation of early body ornaments catalyzed the development of cultural group identity}

A prehistorian looking into the origins of cultural taste from the long-term perspective of archaeology would probably start by asking: When did primarily aesthetic objects such as ornaments appear? Considering the bias inherent in the archaeological record, this is a difficult question to answer with confidence. It would probably be fair to say though that, before seeking degradation-resistant materials, which are not easy to procure and work with, early humans would have made beads from directly available but perishable materials (Iliopoulos 2016a: 261). The ethnographic record abounds with examples of beads made from insect body parts and plant materials (Ruddle 1973; Mehra et al. 1975; Francis 1984; Carey 1986; Dubin 1987, Dubin 2009; Simak and Dreibelbis 2010) as well as non-beaded forms of ornamentation, such as furs, skins, and feathers (Mayr 1907; Turner 1980; Carey 1986). Given the fact, however, that these weathering-sensitive forms of material culture are unavailable, we have no choice but to associate the origins of early body ornamentation with degradation-resistant artefacts such the Blombos beads. Looking at the archaeological evidence one is 
therefore justified in positing that humans had definitely developed an aesthetic taste for body ornamentation by approximately 75 thousand years ago. Despite the number of other options available, Palaeolithic humans seem to have had a particular affinity for Nassarius shells, which must have been chosen due to their small size, rounded shape, and smooth texture (Bar-Yosef Mayer 2015: 82). It should therefore be reasonable to suggest that the artefacts retrieved must have adhered to general rules, even if not symbolic ones at that (Iliopoulos 2016a; also see Kissel and Fuentes 2017).

While addressing the chronological version of "when" the capacity for sign use appeared is without doubt a crucial endeavor in its own right, it does not account for the ontological dimension of prehistoric semiogenesis, an aspect that needs to be explored if we hope to find out more about the events that drove the evolution of material signification. This section thus seeks to examine a particular ontological issue at the heart of the debate on early body ornamentation: How did early body ornaments come to function as indicators of cultural/ group identity? From the long-term perspective of archaeology, it would make sense to start by looking for evidence of creative material engagement in changing aesthetic ideals, as these are revealed by the perforated Nassarius kraussianus tick shells found in different stratigraphic layers at Blombos. According to an experimental study conducted by Vanhaeren and her colleagues (2013), the beads unearthed from the upper two levels appear to have been knotted in floating pairs of dorsally joining shells, whereas those recovered from the lower two levels seem to have been continuously strung with alternate orientation of the shells. This change in the mode of stringing beads reveals a transformation in the ideals that governed their aesthetic appreciation (and perhaps their conceptual interpretation). In other words, the hierarchization of the ornament-induced habits of feeling (and possibly thought) changed at least once for the Blombos Cave inhabitants, who occupied the site during (at least) two phases, as is revealed by recent evidence of trampling modifications (Reynard and Henshilwood 2018). Evidently then, there was some sort of change in the taste for ornamentation, at least with regard to stringing. But why and how did that change come about?

In the hundreds if not thousands of years that bead-use spanned at Blombos (Vanhaeren et al. 2013: 514), various creative events could have taken place, even if not deliberately planned. As I have argued elsewhere (Iliopoulos 2016a: 262-263), the origins of body ornamentation may lie in random events, such as the accidental covering of one's body with ochre originally used in "practical" tasks (e.g. tanning and preserving hides, conferring medicinal qualities, and manufacturing ochre-based adhesives used in the hafting of tools). Social counterparts need no special reason to spontaneously start imitating such an event. 
Imitating a non-adaptive behavior is something chimpanzees have also been observed to engage in. As was recently reported, wild chimpanzees were seen placing a stiff, straw-like blade of grass in their ears, after an adult female chimpanzee started doing it (van Leeuwen et al. 2014). Such is the imitative propensity of these primates that this seemingly useless activity was maintained even after its instigator had died. Although we cannot directly observe whether MSA humans had been behaving in the same way, it would be reasonable to surmise that imitation played an important role in the evolution of aesthetic practices. As Donald (2006) extensively argues, hominins' innate and universal capacity for mimesis must have been a driving factor in the evolution of art because all art is essentially mimetic in style (see also Ranta 2016; Parker 2017).

This is not however to imply that ornamental styles spread through imitation simply because ornaments have some qualities (e.g. color, shininess) which humans happened to find naturally-appealing. From a pragmatic point of view, what we find appealing relies heavily on the effects it has on us - and these effects may be largely the product of thought, rather than mere unadulterated affect. While certain objects (e.g. shiny gold nuggets) might have become agentive because their aesthetic qualities (e.g. shininess and color) are emotionally meaningful (Garofoli 2015: 813-815), it should also be recognized that artefacts could well have become aesthetically appealing because of their agentive nature. In this case, the use of early body ornaments to decorate one's body could have come to be guided by aesthetic ideals as they would have conferred the adorned individual with agentive power through their significative function. Considering how the significative objects and practices of a group can have profound epigenetic effects on the development of its members (Sinha 2015), we can expect that semiotically-meaningful material culture would have actively shaped the ideals and ideas of our ancestors as they were born and raised in such contexts. In other words, what early humans came to think of as appealing (and by extension unappealing) would have been founded on interpretive habits of feeling and thought formed as their sign-inundated social lives unfolded in the aesthetic and symbolic niches they inherited from previous generations.

It should thus follow that a taste for material culture would have been cultivated along the lines of group-specific ideals. Aesthetic judgements and the hyper-generalizations thereof are culturally-specific because the aspects of material forms that the senses have been educated to appreciate, depend on the sensorium in which these operate. As Gosden (2001) points out, identifying the senses that appear to have been emphasized in different cases might illuminate the nature of the social groups in which the discovered artefacts had been operating. He specifically suggests that "an emphasis on the intimate contact 
of touch, taste or (to a lesser extent) smell might indicate that objects exercised their effects in and on small groups, whereas a regular appeal to sight or hearing might allow for social effects within a larger, more distanced group" (Gosden 2001: 165). Given that ornaments are mainly appreciated through vision, they seem to have functioned within sizeable and distant social groups.

This might have been the case in South Africa, where ornaments had been worn during intense occupations of the Blombos Cave. However, since the Blombos Cave is the only South African site (to date) that has produced Nassarius kraussianus shell beads, there is currently no definitive evidence that the Blombos beads functioned within distant social groups. On the other hand, the Moroccan archaeological record seems to allow for such a postulation due to the fact that perforated Nassarius shells - of the gibbosulus species though - have been discovered at four Middle Palaeolithic sites. ${ }^{8}$ D'Errico and his colleagues (2009: 16055) take the fact that three of these (i. e. Taforalt, Ifri n'Ammar and Rhafas) are located 40-60 km inland, in combination with the relatively small number of beads they have yielded, and the discovery of unperforated shells at Taforalt, to suggest the presence of organized exchange networks. The possibility of sociocultural links between these sites is further reinforced if we consider their cultural and temporal proximity. Not only are they all associated with the Aterian technocomplex, but the ages of the shell beads also demonstrate significant overlap (i.e. 85-82 kya ago at Taforalt, 82 kya ago at Ifri n'Ammar, and 80-70 kya ago at Rhafas) (d'Errico et al. 2009). This could perhaps suggest the presence of widespread artistic practices, purposefully perpetuated by humans discovering the aesthetic effects of signification.

The interactions of humans inhabiting the Moroccan sites - or, for that matter, the interactions of people residing at Blombos Cave with inhabitants of other proximal sites - would have given them the opportunity to think about the aesthetic ideals that make their material culture really theirs, so to speak. By coming to assume a metacognitive take on the hierarchized habits of feeling incited by group-specific artefacts, early humans would have essentially started recognizing these objects as integral elements of an Ego-culture. Of course, the members of an ornament-using group would not have come to such a realization while being isolated from other social groups. As we are informed by Sonesson (2016: 30), rather than being preoccupied with a Culture in its singularity, cultural semiotics is geared towards the relationships between cultures.

8 According to a recent phylogenetic study on the Nassariidae family, the name to be used for the Atlantic/Mediterranean clade is Tritia (Galindo et al. 2016). To this extent, what prehistorians had been referring to as Nassarius gibbosulus is now called Tritia gibbosulus. 
According to the Lund model, it is through communicative events that Ego-, Alter, and Alius-cultures are shaped (Sonesson 2016: 37). Following this take on cultural encounters, I suggest that early ornament-related Ego-cultures would have evolved against the backdrop of Alius-cultures that have yet to discover or adopt self-adornment. For the members of the Ego-culture, the non-practitioner would have been an Alius with whom cultural communication was impossible, either due to lack of a capacity for understanding or due to lack of willingness to understand. Whatever the case, the value of practicing body ornamentation in one's own group could have only been fully grasped by comparison to groups lacking it completely. In fact, the conclusions that the members of an Egoculture had reached through such a comparison would have been further accentuated by evaluating the relation of Alius-cultures to other ornamentusing groups.

It seems indeed quite possible that prehistoric shell beads such as those found in Africa evolved along Alter-cultures that also employ ornaments, which might have been made though from perishable materials that we cannot now detect. For an archaeologically-visible example of contemporaneous ornamental traditions however, we could turn to the richer Aurignacian record from the European Upper Palaeolithic. In their comprehensive study, Vanhaeren and d'Errico (2006: 1108) identified one hundred and fifty-seven distinct bead types from ninety-eight European Aurignacian sites in continental Europe and the Near East. The diverse range of materials used for their manufacture includes (in order of frequency): shells, teeth, ivory, stone, bone, deer antler, belemnite, nummulite, ammonite, sea urchin, and amber. In such an ornament-rich environment, Ego-cultures practicing a specific tradition would have inevitably come to see group-specific ideals of other peoples as telling of another Ego, an Alter. Attending to the similarities and differences between ornaments worn by members of different groups would have no doubt played an essential role in coming to conceptualize one's material culture as an entity with aesthetic ideals of its own. Moreover, being raised among group-specific objects would have helped young individuals develop an aesthetically-founded sense of being part of a specific cultural tradition. As Portera (2016: 44) aptly points out: "To share a particular aesthetic heritage became a sign of commitment and belonging to the community, and a means of distinguishing (or "selecting”) one's own community from other groups, particularly as human populations became larger and more extended."

As integral components of an Ego-culture, prehistoric shell beads would have been secondary iconic signs so long as they functioned as signs of themselves, of some of their properties (e.g. roundness, value, portability, and accessorization), and of the class of which they form part (e.g. ornamental 
Nassarius shell beads). Understanding them as icons proper would have undeniably required some kind of cultural knowledge. It would probably be safe to say that, in order to identify beadworks as representative signs of Nassariusbased body ornamentation, one would have had to be familiar with the practice. Otherwise, why should these suspended objects be seen as ornaments per se? Cognitively speaking, these artefacts would have functioned as a scaffold for the blending of group-specific material forms and cultural identity (Figure 1). This new material sign would have been significative in the strict sense of the term, as it would have satisfied the criteria delineated by Sonesson (2006, 2007, 2010, 2012). For one, it would have been composed of two distinct parts (the beadwork was the Expression, and its "cultural identity" was the Content), which did not overlap in time and/or space (while the beadwork was in the here and now, its "cultural identity" was spatiotemporally extended) and were perceived to be of different nature (the beadwork was material, whereas "cultural identity" was mental). Moreover, the two entities of the material sign would have been in a doubly asymmetrical relation (despite the fact that it is the beadwork that came

Material space

Shell beads

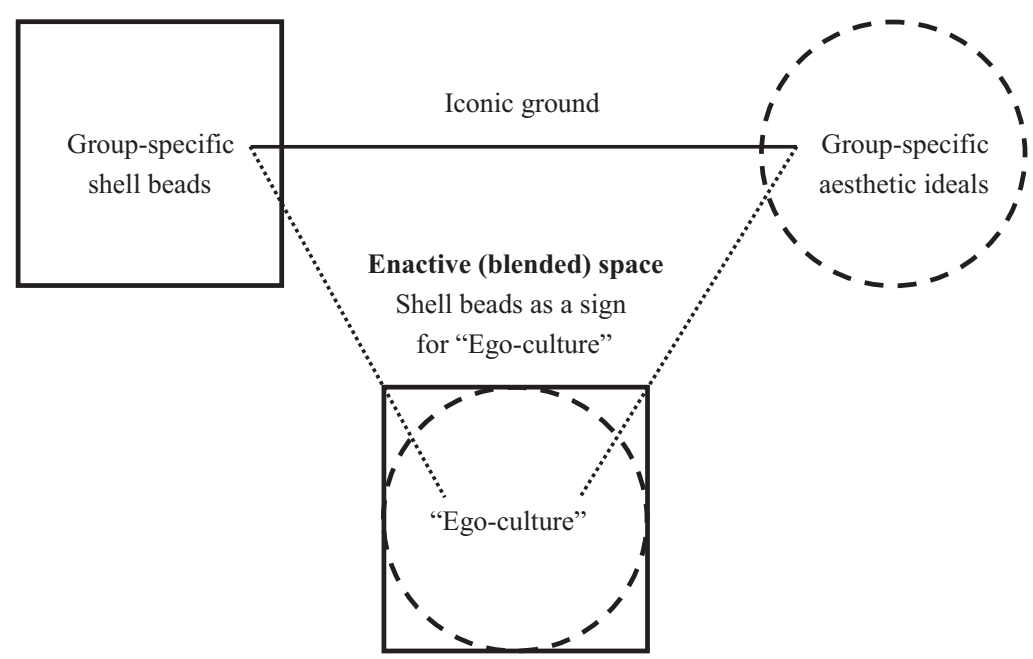

Figure 1: The iconic material sign for "Ego-culture" as a conceptual blend with shell beads as material anchors. 
to one's immediate attention, it is "cultural identity" that was the focal point). At this point, beadworks and "cultural identity" would have been subjectively differentiated, in that the former was directly given and nonthematic, whereas the latter was only indirectly present and thematic.

In terms of Peirce's tenfold typology, appreciating artworks such as the Blombos beads for their inherent qualities would have entailed the conceptualization of a denotative iconic rule (Rhematic Iconic Legisign - class 5), according to which such beadworks signify an aesthetically meaningful Ego-culture. As can be seen in Figure 2, this denotative iconic rule would have manifested itself in the physical world as denotative iconic instantiations (Rhematic Iconic Sinsigns - class 2), according to which particular beadworks signify a specific Ego-culture. It is through encounters with these individual instantiations of general rules, which Peirce (CP 2.246) calls Replicas, that pleasurable feelings would have been embodied (Rhematic Iconic Qualisigns - class 1).

5. Denotative iconic rule

(Rhematic Iconic Legisign)<smiles>C[Al]1CC1</smiles>

2. Denotative iconic instantiation

(Rhematic Iconic Sinsign)

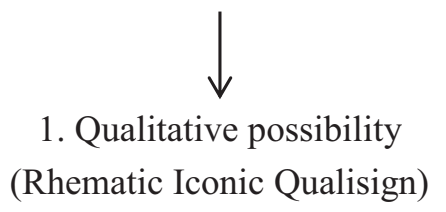

Figure 2: The types of signs in Peirce's tenfold typology involved in the mediation of the meaning according to which such beadworks signify an aesthetically meaningful "Ego-culture." The black arrow points towards an embodied lower-order sign that provides the foundations for a higher-order sign, while the green arrows point towards a "peculiar" Sinsign that is a realworld instantiation (Replica) governed by a general rule (Legisign).

In the face of positive emotional reactions when in the possession of aesthetically meaningful artefacts, early humans would have naturally sought for a way to prolong the perceived benefits by attaching them to their bodies (Garofoli 2015: 813). The act of wearing material signs iconic of an Egoculture would have inevitably scaffolded an indexical mode of signification, 
wherein body ornaments came to signify the "cultural identity" and by extension, the "cultural group affiliation" of their wearer. This novel concept would have emerged, in this instance, through a perceptual association between decorated individuals and their possession of group-specific shell beads. From a cognitive perspective, wearing particular beadworks would have enabled a process of conceptual blending that established the beadwork as a sign for its wearer's cultural identity and group affiliation (Figure 3). As was the case for the iconic material sign for Ego-culture, this newly emergent indexical sign would also have satisfied the criteria for proper sign function. At the risk of repeating myself, I would like to make clear that it too would have been comprised by two distinct parts (the beadwork was the Expression and the wearer's cultural identity was the Content), which did not go over into each other in time and/or space (while the beadwork was in the here and now, the wearer's cultural identity was spatiotemporally extended), and were perceived to be of different nature (the beadwork was material, whereas the wearer's cultural identity was mental). In addition, the material and mental

Material space

Shell beads

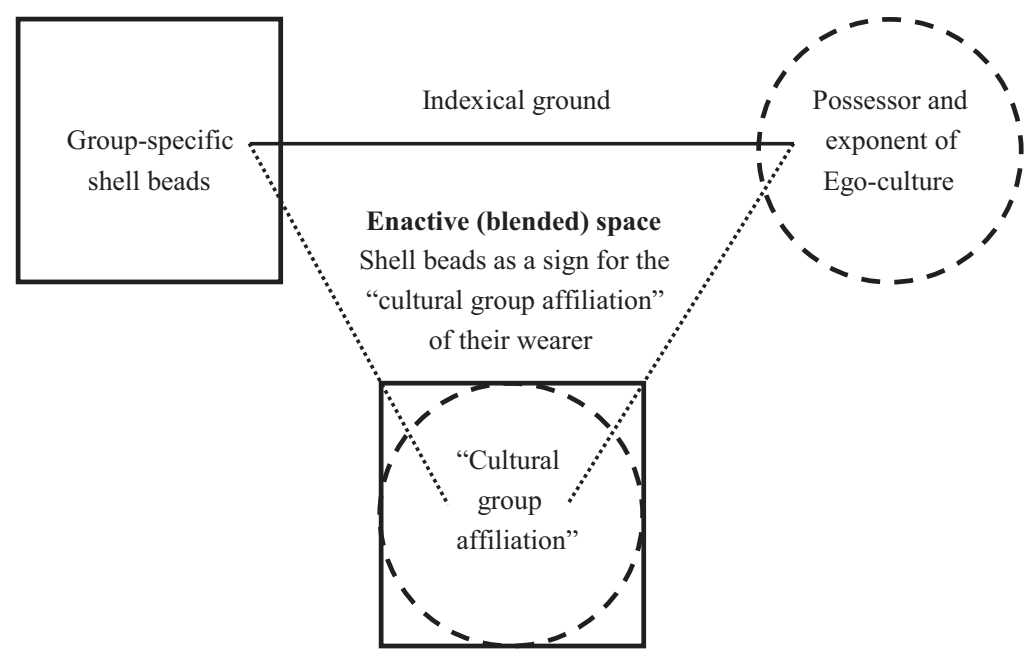

Mental space

Cultural identity of the wearer

Mapping/relevance

Projection

Figure 3: The indexical material sign for "cultural group affiliation" as a conceptual blend with shell beads as material anchors. 
entities comprising this novel sign for "group affiliation" would have been in a doubly asymmetrical relation (despite the fact that it is the beadwork that came to one's immediate attention, it is the wearer's cultural identity that was at the centre of attention). Once this stage had been reached, beadworks and "cultural group affiliation" would have been subjectively differentiated, since the former was directly given and non-thematic, whereas the latter was only indirectly present and thematic.

The interpretive habit through which a beadwork would have been understood as a sign for such a concept was a denotative iconic rule (Rhematic Iconic Legisign class 5) which, once the beads had been worn, became associated with a denotative indexical rule (Rhematic Indexical Legisign - class 6) indicating the wearer whose "cultural group affiliation" was of concern. The meaning of the resulting informative indexical rule (Dicentic Indexical Legisign - class 7) was that such beadworks signify their wearer's "cultural group affiliation.” As can be seen in Figure 4, this informative indexical rule would have been used to guide the interpretation of informative indexical instantiations of decorated individuals (Dicentic Indexical Sinsigns class 4). In turn, these Replicas embodied a denotative indexical instantiation

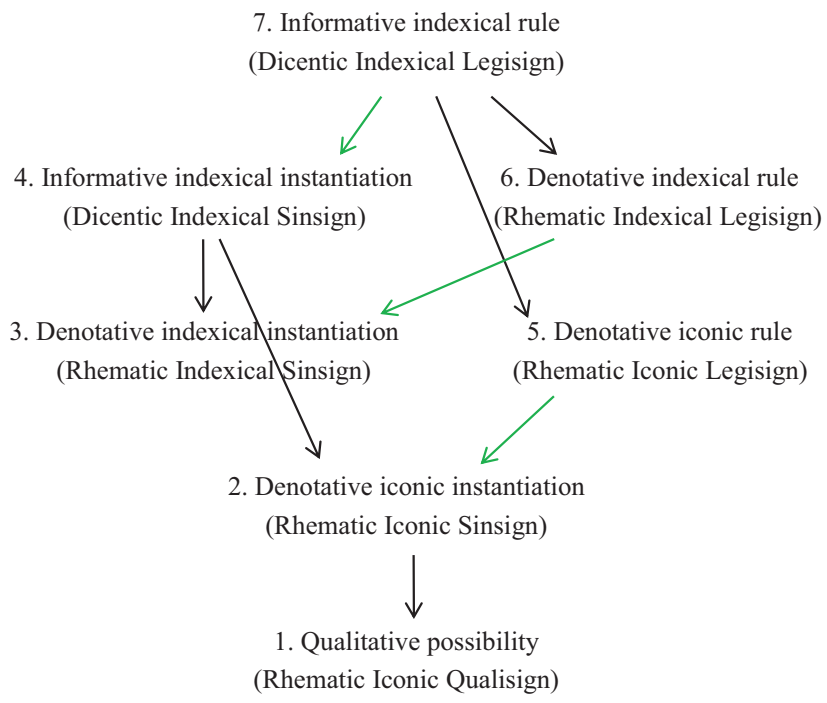

Figure 4: The types of signs in Peirce's tenfold typology involved in the mediation of the meaning according to which such beadworks signify their wearer's "cultural group affiliation." The black arrows point towards the embodied lower-order signs that provide the foundations for higher-order signs, while the green arrows point towards "peculiar" Sinsigns that are realworld instantiations (Replicas) governed by general rules (Legisigns). 
(Rhematic Indexical Sinsign - class 3) whose meaning was that a particular beadwork signifies a capacity of its wearer, and a denotative iconic instantiation (Rhematic Iconic Sinsign - class 2) whose meaning involved a particular beadwork signifying "group affiliation.” Finally, the latter would have embodied certain qualitative possibilities (Rhematic Iconic Qualisigns - class 1) which included "culture," "group" and "affiliation."

Having considered the multiple layers of meaning involved in the indexical signification of cultural group affiliation, it is important to note that ornaments would not only have referenced their meaning to outsiders, they would have also concomitantly conferred it upon members of the group. Through their abductive and performative function, ornamental indices would have come to elicit a sense of belonging by generating not just logical, but also emotional Interpretants. In terms of Peirce's theory of aesthetics, ornaments would have strengthened the belongingness felt by their wearers, who would have experienced this habituated quality of feeling as a group-specific ideal. It is not hard to see how the habit of feeling associated with the sense of belonging would have been instrumental in strengthening a group's cohesion. As has been argued by Gamble (2007, 2010, 2012; Gamble et al. 2011), the amplification of emotions during the Palaeolithic strengthened and extended the social bonds between hominins. Ornamental shell beads would have certainly played a significant part in what he has famously referred to as a "release from proximity" (Gamble 1998) by helping early social groups, such as the occupants of the Moroccan sites or the Blombos Cave inhabitants, establish a cultural identity of their own - a cultural identity that could transcend the here and now thanks to the mobility and durability of matter. The synchronic and diachronic properties of art and artefacts would have been integral in shaping the evolutionary paths traversed by past peoples. From the perspective of narrative-oriented approaches to art, such as Carroll's (2001), it could then be argued that the historical narratives built along these evolutionary trajectories may have helped link each new work of art with other bona fide cases. Carroll calls these stories about artistic objects and performances, "identifying narratives." Group narratives about identity have been recently shown to emerge from a reflective attribution of joint agency, thus contributing to the development of a stable we (Gallagher and Tollefsen 2019). It should be fair to argue then that the historical and cultural narratives associated with early body ornaments would have been integral in fostering a sense of community otherwise seen as a communal awareness founded on a new kind of Egoculture. 


\section{Discussion: Considering some archaeological accounts on the origins of aesthetically meaningful ornamentation}

Having now applied the cognitive semiotic framework to the case of early body ornamentation, it is time to return to an issue raised early on in the paper: Were the aesthetic rules associated with ornamental styles guided by "symbolic" codes that had been conventionally-agreed upon? Were they instead the result of perceiving others' attraction to interesting materials? Or were they actually produced through the perceptual and conceptual interpretation of material signs? Keeping in mind the points made above, let us start by evaluating the first supposition, which is the one linked to the "symbolocentric" approach, before proceeding with the second one, that associated with Radically Enactive Cognitive Archaeology. Only after comparing RECA with the cognitive semiotic theory outlined above will we be able to ultimately arrive at the third of the alternatives, in the concluding section of this paper.

\section{1 "Symbolocentric" approach}

As was briefly mentioned in the introduction, prehistoric artefacts are often associated with abstract properties through conventional connections. Henshilwood and Dubreuil (2011: 391), for instance, associate personal ornaments with "good taste" through what they deem to have been a "symbolic" link. Reflecting on their approach, they write: "We think that this use is in line with the Peircean notion of symbol, although maybe not with any understanding of it." While they are absolutely right in that the Peircean symbol is associated with conventionality, I personally find it preferable to study habit-involving material signs such as early body ornaments through Sonesson's interpretation of Peircean semiotics, seeing how he recognizes that icons and indices can also be conventionally-guided. Though some iconic and indexical signs require little familiarity with conventions, mostly relying on direct perception (i. e. primary icons and performative indices), others can rely heavily on abstraction and prior knowledge (i. e. secondary icons and abductive indices). The idea that conventions are exclusive to symbolism precludes us from associating prehistoric artefacts with a semiotic function rigidly grounded in real-world connections to other things or events. In this regard, a semiotic theory that helps us appreciate how material signs (in Sonesson's strict sense of the term) can share both 
qualities and spatiotemporal contexts with what they stand for, in a conventional sort of way, could prove instrumental.

If, however, the ways in which the physical world partakes in material culture are not brought to the forefront, we are bound to find ourselves assuming a hylomorphic explanation of how cultural conventions must have been created at a particular time and place. This is probably the reason why the localized emergence of artefacts, such as shell beads, tends to be attributed to an inventive process through which predefined templates were projected onto passive material substrates by means of deliberate and purposeful behavior. According to Cole (2015: 79) for example, early body ornamentation had been deliberately produced to function as the physical expression of abstract notions relating to identity. From this epiphenomenalist point of view, matter partook in human lives mainly by taking the form imposed on it. Accepting though that objects were used to store predefined forms and abstractions does not really account for how the pertinent templates had been defined in the first place, nor does it explain how the meanings communicated through artefacts first came to be, leaving the development of stylistic preferences practically unaccounted for. One way of explaining the co-emergence of forms and meanings involves tracing their discovery through our ancestors' skillful engagement with material worlds holding much semiotic potential.

Should however the active role that the physical world plays in creative processes go unnoticed, then it is a Neo-Darwinian take on the origins of material culture that is most compatible as far as an evolutionary theory is concerned. It seems to me though that opting for a linear and adaptationist point of view entails making a pair of interrelated assumptions about prehistoric artefacts: i) that cultural innovations are preceded by biological advances; and ii) that, much like biology, culture serves adaptive purposes.

For an example of the former, consider how Henshilwood and Dubreuil (2011: 367) attribute the evolution of early body ornaments to the functional reorganization of the temporoparietal junction that took place within our lineage, on the basis that the temporal and parietal cortices are the main cortical areas implicated in our ability to "see" how other people see us. While not aiming to undermine the importance of neuroscientific insights, Malafouris (2011a: 386) pointed out though that prioritizing brain reorganization over behavioral or material changes is problematic, because the flow of cause and effect between brain and material culture is in fact bidirectional. To this extent, the theory of material engagement tells us that biological and cultural elements are best taken to have co-developed in an inextricably entwined manner, much in the way portrayed by post-genomic metatheoretical models, such as Developmental Systems Theory (Griffiths and Gray 1994; Griffiths and Stotz 
2000; Oyama et al. 2001) and Probabilistic Epigenesis (Gottlieb 2003, Gottlieb 2007). It is therefore important that one remains sensitive to the rich array of ways in which plastic brains and objects could have come together during the course of human evolution to bring forth unique ways of thinking. By attending to the metaplasticity of human-thing interactions, we can conceive evolution as a dynamic process that is not only phylogenetically-, but also ontogeneticallyand developmentally-sensitive.

As for the second of the Neo-Darwinian assumptions, remember that artefacts such as beads are generally taken to have evolved as an adaptation that works as a kind of information technology. It is usually accepted that their primordial role rests in indicating where one stands in the market of reputation (e. g. Henshilwood and Dubreuil 2011: 391). In other words, their wearers had been arguably using them to propagate their abstract identity to others (e. g. Cole 2015: 79). It is precisely this communicative function that is taken to have been the case even in the unlikely (for most) scenario that body ornaments had served a merely aesthetic function. As Kuhn and Stiner (2007: 42) characteristically put it: "Even the apparently simple aim of making oneself 'look good' is sending a message to someone we hope will consider us attractive or at least attentive to our appearance." From this instrumentalist point of view, ornaments are apparently conceived as instruments meant to address social concerns. While I do not aim to undermine the importance of adaptation in any way (so long as the focus of natural selection is placed on the organism in its epistemic niche), it is important to note that cultural forms and meanings can also be attributed to the unique propensity that humans have for making. Taking into consideration our remarkable adeptness at finding new varieties of materials to think through and about, we arrive at an account of evolution which treats innovations less like premeditated inventions and more like enactive discoveries (Malafouris 2014).

\subsection{MET-inspired approaches}

Evidently then, illuminating the nature, emergence, and evolution of material culture requires ascribing artefacts with an active role - a task undertaken by MET's enactive epistemology. This new school of thought in cognitive archaeology allows us to account for the way in which the material forms and mental concepts involved in the practice of self-adornment must have been apprehended in the first place. From the vantage point of MET, stringing shell beads around one's body came to communicate information about their wearer through a prolonged process of making and interpreting. That said, attempts 
to explain the origins of early body ornamentation through MET and enactivism are not without their differences (see Garofoli and Iliopoulos 2019). While Radical Enactive Cognitive Archaeology and our cognitive semiotic theory were both born out of the same need (i. e. the need to account for the material dimensions of cognition), these variants assume different perspectives on the topic of material signification.

According to RECA, we need to make a distinction between non-representational signs, which are content-less because they only depend on co-variance of "external" and "internal" states, and representational signs, which are content-full because they depend on language. The pragmatic and enactive theory of cognitive semiotics I have tried to put together here does not adhere to this distinction, opting instead for an account where all material signs are by definition representational, albeit not of the internalist and computational variety espoused by Cartesian dualism, but in the mediational sense of Peirce's triadic semiotics. By drawing upon Peirce's (Aydin 2015) and Malafouris' (2013: 85) claims that the mind has no physical location per se, I have elsewhere replaced the internalist with a locationally-neutral account of cognition (Iliopoulos 2019: 49). In moving away from the internal/external divide, we could perhaps substitute Cartesian representations with mediated interpretations driven by the generative force of semiotic objects (whether artefacts or previous thoughts) and the hermeneutic nature of an extended mind (Iliopoulos 2019: 59).

From the perspective adopted in this paper, the co-variance invoked by RECA cannot sufficiently explain "perceptually-dominant" signs such as primary icons and performative indices, because a correlation between internal and external states cannot really account for the fact that the users of such signs end up cognizing an indirectly present and thematic aspect of a person, thing or event, despite engaging with a directly given and nonthematic entity. In bringing Sonesson's notion of sign function into the discussion, the cognitive semiotic theory outlined above seeks to illuminate how - what RECA calls - "contentless" signs still rely on habits of mediated interpretation, rather than re-imaginings of internal/external co-variance. For instance, a photograph cannot be really grasped as a primary iconic sign, unless we recognize that it stands for a faraway person, object, or place in a particular sort of way - that is, unless we understand that it re-presents a thematic aspect of a polythematic someone or something that is not however immediately present.

As for "abstraction-heavy" signs such secondary icons and abductive indices, the framework outlined in this paper does not require these kinds of sign to depend on language for their Content. Much like in the case of primary icons and performative indices, the meaning of these signs can still rely on the Expression's relevance to an actual object found in the physical world 
(e. g. particular stylized ornaments). To prevent any misunderstanding, I should make it abundantly clear that it is not the sign function that ascribes a Content to an Expression. Conversely, it is the capacity for sign function that emerges from perceiving a relation between two "things," and attending to the way in which one of these (i. e. the one that ends up being the sign's Expression) mediates a thematic perspective of the other (i.e. the one that ends up being the sign's Content). As far as human evolution is concerned then, our invocation of the capacity for sign function should not be taken as a suggestion that a sub-personal architecture capable of processing signs would have already been there. What is argued here is in fact quite the opposite. In having to evaluate the truthfulness of informative signs (i. e. Dicisigns), early humans would have had the opportunity to reflect on perceptual cues and prior experience. As has been already suggested, it is by coming to think about thinking that the biocultural mechanisms required for deliberate sign-use would have been developed.

Having now seen how our cognitive semiotic framework differs from RECA's take on semiotics, it should come to no surprise that the two enactive variants describe the origins of an aesthetic preference for ornamentation in their own unique ways. As RECA sees it, feelings emerge from the direct perception of the embodied reactions of others to intrinsic qualities of matter. From this point of view, various objects would have become agentive due to their aesthetically appealing properties (e.g. texture and color). A nugget of gold, for instance, might have been turned into an ornament due to the emotion-inducing effects of its shiny and gold appearance (Garofoli 2015: 813-815). A “natural” propensity for certain forms may well play a significant part in what early humans came to consider beautiful, yet the polymorphic manifestation of ornamentation in the ethnographic and archaeological literature suggests additional processes at play. While delving into a detailed examination of the full suite of reasons different people find different things appealing falls beyond the scope of this paper, it should be fair to accept that aesthetic tendencies are shaped by the agentive effects of what human groups see as conceptually-significative artefacts - at least to the extent of what has been argued above.

\section{Conclusion: Attuning to the co-evolution of ideas and ideals}

We must therefore ultimately arrive at the third alternative posed when pondering the development of aesthetic ideals - that is, the one attributing the appearance of styles and preferences to the perceptual and conceptual interpretation of agentive 
material signs. As has been claimed, aesthetic forms and ideals governing early body ornamentation probably developed in group-specific contexts of material signification. This paper sought to highlight the fact that aesthetics and feelings are strongly interconnected to thoughts and concepts (see also Johnson 2008). Ideas such as those governing cultural identity were likely founded on aesthetic ideals, themselves shaped during semiogenetic processes involving other ideas, as are for instance those associated with the signification of personal identity (e. g. "status" etc.). Evidently then, aesthetics, symbolism, and everything in between, are aspects of material signification that come together in common ontological loci. As was proposed in the evolutionary account sketched above, the aesthetically- and (perhaps) symbolically-rich developmental contexts within which early humans were likely raised must have honed their interpretive skills, producing feelings, actions, and thoughts that subsequently led to new enactive discoveries. One of these innovations was the use of early body ornaments for the (abductive and performative) signification of cultural group affiliation. As we have seen, the feelings of belongingness brought forth through protracted processes of creative material engagement must have in turn provided the semiotic scaffolding required for identifying narratives. By attending to the interrelation between form, effect, and affect, members of social groups would have come to appreciate the ways in which their ornamental culture resembles and differs from that of neighboring groups. If this were the case, the metacognitive and meta-emotional understanding of early body ornaments that was eventually achieved probably catalyzed the formation and communication of distinct group identities. It should thus be fair to conclude that the evolution of Egocultures was to an extent driven by the co-development of the aesthetic ideals and conceptual ideas associated with early body ornamentation.

Acknowledgements: I would like to thank Göran Sonesson for inviting me to present a paper at the symposium on The Making of Them and Us, as well as for his feedback on an earlier draft submitted to the homonymous special issue. Thanks for their comments are also due to two anonymous reviewers, as well as to Anna Cabak Rédei for her editorial assistance.

\section{References}

Abadía, Oscar M. \& April Nowell. 2015. Palaeolithic personal ornaments: Historical development and epistemological challenges. Journal of Archaeological Method and Theory 22. 952-979.

Aydin, Ciano. 2015. The artifactual mind: Overcoming the "inside-outside" dualism in the extended mind thesis and recognizing the technological dimension of cognition. Phenomenology and the Cognitive Sciences 14(1). 73-94. 
Barton, Nick \& Francesco d'Errico. 2012. North African origins of symbolically mediated behaviour and the Aterian. In Scott Elias (ed.), Origins of human innovation and creativity, 23-34. Amsterdam: Elsevier.

Bar-Yosef, Offer. 2002. The Upper Paleolithic revolution. Annual Review of Anthropology 31. 363-393.

Bar-Yosef Mayer, Daniella E., Bernard Vandermeersch \& Ofer Bar-Yosef. 2009. Shells and ochre in Middle Paleolithic Qafzeh Cave, Israel: Indications for modern behavior. Journal of Human Evolution 56. 307-314.

Bar-Yosef Mayer, Daniella E. 2015. Nassarius shells: Preferred beads of the Palaeolithic. Quaternary International 390. 79-84.

Bednarik, Robert G. 2008. Beads and cognitive evolution. Time and Mind: The Journal of Archaeology, Consciousness and Culture 1. 285-318.

Bergson, Henri-Louis. 1998 [1911]. Creative evolution, Arthur Mitchell (trans.). Mineola, NY: Dover. Bouzouggar, Abdeljalil, Nick Barton, Marian Vanhaeren, Francesco d'Errico, Simon Collcutt, Tom Higham, Edward Hodge, Simon Parfitt, Edward Rhodes, Jean-Luc Schwenninger, Chris Stringer, Elaine Turner, Steven Ward, Abdelkrim Moutmir \& Abdelhamid Stambouli. 2007. 82,000-year-old shell beads from North Africa and implications for the origins of modern human behavior. Proceedings of the National Academy of Sciences 104. 9964-9969.

Cabak Rédei, Anna. 2007. An inquiry into cultural semiotics: Germaine de Staël's autobiographical travel accounts. Lund: Lund University.

Cappuccio, Massimiliano L. \& Stephen V. Shepherd. 2013. Pointing hand: Joint attention and embodied symbols. In Zdravko Radman (ed.), The hand, an organ of the mind: What the manual tells the mental, 303-326. London \& Cambridge, MA: The MIT Press.

Carey, Margret. 1986. Beads and beadwork of East and South Africa. Princes Risborough: Shire Publications.

Carey, Margret. 1998. Gender in African beadwork: An overview. In Lidia D. Sciama \& Joanne B. Eicher (eds.), Beads and bead makers: Gender, material culture and meaning, 83-93. Oxford: Berg Publishers.

Carroll, Noël. 2001. Beyond aesthetics: Philosophical essays. Cambridge: Cambridge University Press.

Carter, Adam J., Emma C. Gordon \& Orestis Palermos. 2016. Extended emotion. Philosophical Psychology 29(2). 198-217.

Chase, Philip G. \& Harold Lewis Dibble. 1987. Middle Paleolithic symbolism: A review of current evidence and interpretations. Journal of Anthropological Archaeology 6. 263-296.

Cole, James. 2015. Hominin language development: A new method of archaeological assessment. Biosemiotics 8(1). 67-90.

Colombetti, Giovanna \& Evan Thompson. 2008. The feeling body: Toward an enactive approach to emotion. In Willis F. Overton, Ulrich Müller \& Judith Newman (eds.), Developmental perspectives on embodiment and consciousness, 45-68. New York: Lawrence Erlbaum Associates.

Deacon, Terrence W. 1997. The symbolic species: The co-evolution of language and the brain. New York: W. W. Norton \& Company.

d'Errico, Francesco, Christopher Henshilwood, Graeme Lawson, Marian Vanhaeren, Anne-Marie Tillier, Marie Soressi, Frédérique Bresson, Bruno Maureille, April Nowell, Joseba Lakarra, Lucinda Backwell \& Michèle Julien. 2003. Archaeological evidence for the emergence of language, symbolism, and music - An alternative multidisciplinary perspective. Journal of World Prehistory 17. 1-70. 
d'Errico, Francesco, Christopher Henshilwood, Marian Vanhaeren \& Karen van Niekerk. 2005. Nassarius kraussianus shell beads from Blombos Cave: Evidence for symbolic behaviour in the Middle Stone Age. Journal of Human Evolution 48. 3-24.

d'Errico, Francesco, Marian Vanhaeren \& Lyn Wadley. 2008. Possible shell beads from the Middle Stone Age layers of Sibudu Cave, South Africa. Journal of Archaeological Science 35. 2675-2685.

d'Errico, Francesco \& Marian Vanhaeren. 2009. Earliest personal ornaments and their significance for the origin of language debate. In Rudolf Botha \& Chris Knight (eds.), The cradle of human language, 16-40. Oxford: Oxford University Press.

d'Errico, Francesco, Marian Vanhaeren, Nick Barton, Abdeljalil Bouzouggar, Henk Mienis, Daniel Richter, Jean-Jacques Hublin, Shannon P. McPherron \& Pierre Lozouet. 2009. Additional evidence on the use of personal ornaments in the Middle Paleolithic of North Africa. Proceedings of the National Academy of Sciences 106. 16051-16056.

Donald, Merlin. 2006. Art and cognitive evolution. In Mark Turner (ed.), The artful mind: Cognitive science and the riddle of human creativity, 3-20. Oxford: Oxford University Press.

Dubin, Lois S. 1987 . The history of beads: From 30,000 B.C. to the present. London: Thames \& Hudson.

Dubin, Lois S. 2009. The worldwide history of beads: Ancient, ethnic, contemporary. London: Thames \& Hudson.

Fauconnier, Gilles \& Mark Turner. 2002. The way we think: Conceptual blending and the mind's hidden complexities. New York: Basic Books.

Fernández, Esteban Álvarez \& Olaf Jöris. 2008. Personal ornaments in the early Upper Paleolithic of western Eurasia: An evaluation of the record. Eurasian Prehistory 5(2). 31-44.

Francis, Peter Jr. 1984. Plants as human adornment in India. Economic Botany 38. 194-209.

Galindo, Lee Ann, Nicolas Puillandre, José Utge, Pierre Lozouet \& Philippe Bouchet. 2016. The phylogeny and systematics of the Nassariidae revisited (Gastropoda, Buccinoidea). Molecular Phylogenetics and Evolution 99. 337-353.

Gallagher, Shaun \& Deborah Tollefsen. 2019. Advancing the 'We' through narrative. Topoi: An International Review of Philosophy 38(1). 211-219.

Gamble, Clive. 1998. Palaeolithic society and the release from proximity: A network approach to intimate relations. World Archaeology 29. 426-449.

Gamble, Clive. 2007. Origins and revolutions: Human identity in earliest prehistory. Cambridge: Cambridge University Press.

Gamble, Clive. 2010. Technologies of separation and the evolution of social extension. In Robin Dunbar, Clive Gamble \& John Gowlett (eds.), Social brain and distributed mind, 17-42. Oxford: Oxford University Press.

Gamble, Clive, John Gowlett \& Robin Dunbar. 2011. The social brain and the shape of the Palaeolithic. Cambridge Archaeological Journal 21. 115-135.

Gamble, Clive. 2012. Creativity and complex society before the Upper Palaeolithic transition. In Scott Elias (ed.), Developments in Quaternary science, 15-21. Amsterdam: Elsevier.

Garofoli, Duilio. 2015. Do early body ornaments prove cognitive modernity? A critical analysis from situated cognition. Phenomenology and the Cognitive Sciences 14(4). 803-825.

Garofoli, Duilio \& Antonis Iliopoulos. 2019. Replacing epiphenomenalism: A pluralistic enactive take on the metaplasticity of early body ornamentation. Philosophy \& Technology 32(2). 215-242. 
Gell, Alfred. 1992. The enchantment of technology and the technology of enchantment. In Jeremy Coote \& Anthony Shelton (eds.), Anthropology, art and aesthetics, 40-67. Oxford: Clarendon Press.

Gell, Alfred. 1998. Art and agency: An anthropological theory. Oxford: Clarendon Press. Gibson, James J. 1979. The ecological approach to visual perception. Boston: Houghton Mifflin. Gosden, Chris. 2001. Making sense: Archaeology and aesthetics. World Archaeology 33. 163-167. Gottlieb, Gilbert. 2003. On making behavioral genetics truly developmental. Human Development 46. 337-355.

Gottlieb, Gilbert. 2007. Probabilistic epigenesis. Developmental Science 10. 1-11.

Griffiths, Paul E. \& Russell D. Gray. 1994. Developmental systems and evolutionary explanation. The Journal of Philosophy 91. 277-304.

Griffiths, Paul E. \& Karola Stotz. 2000. How the mind grows: A developmental perspective on the biology of cognition. Synthese 122. 29-51.

Henshilwood, Christopher S. \& Curtis W. Marean. 2003. The origin of modern human behavior: Critique of the models and their test implications. Current Anthropology 44. 627-651.

Henshilwood, Christopher S., Francesco d'Errico, Marian Vanhaeren, Karen L. van Niekerk \& Zenobia Jacobs. 2004. Middle Stone Age shell beads from South Africa. Science 304. 404.

Henshilwood, Christopher S. \& Benoît Dubreuil. 2011. The Still Bay and Howiesons Poort, 77-59 ka: Symbolic material culture and the evolution of the mind during the African Middle Stone Age. Current Anthropology 52. 361-400.

Hoffmeyer, Jesper. 2007. Semiotic scaffolding in living systems. In Marcello Barbieri (ed.), Introduction to biosemiotics: The new biological synthesis, 149-166. Dordrecht: Springer.

Hoffmeyer, Jesper. 2014a. The semiome: From genetic to semiotic scaffolding. Semiotica 198. 11-31.

Hoffmeyer, Jesper. 2014b. Semiotic scaffolding: A biosemiotic link between sema and soma. In Kenneth R. Cabell \& Jaan Valsiner (eds.), The catalyzing mind, 95-110. New York: Springer.

Hutchins, Edwin. 2005. Material anchors for conceptual blends. Journal of Pragmatics 37. 1555-1577.

Iliopoulos, Antonis. 2016a. The evolution of material signification: Tracing the origins of symbolic body ornamentation through a pragmatic and enactive theory of cognitive semiotics. Signs and Society 4. 244-277.

Iliopoulos, Antonis. 2016b. The material dimensions of signification: Rethinking the nature and emergence of semiosis in the debate on human origins. Quaternary International 405 (Part A). 111-124.

Iliopoulos, Antonis. 2019. Material Engagement Theory and its philosophical ties to pragmatism. Phenomenology and the Cognitive Sciences 18(1). 39-63.

Iliopoulos, Antonis \& Duilio Garofoli. 2016. The material dimensions of cognition: Reexamining the nature and emergence of the human mind. Quaternary International 405 (Part A). 1-7.

Iliopoulos, Antonis \& Lambros Malafouris. In Press. Symbols and material signs in the debate on human origins. In Andrew Lock, Nathalie Gontier \& Chris Sinha (eds.), Oxford handbook of human symbolic evolution. Oxford: Oxford University Press.

Ingold, Tim. 2010. The textility of making. Cambridge Journal of Economics 34. 91-102.

Ingold, Tim. 2013. Prospect. In Tim Ingold \& Gisli Palsson (eds.), Biosocial becomings: Integrating social and biological anthropology, 1-21. Cambridge: Cambridge University Press.

Janowski, Monica. 1998. Beads, prestige and life among the Kelabit of Sarawak, East Malaysia. In Lidia D. Sciama \& Joanne B. Eicher (eds.), Beads and bead makers: Gender, material culture and meaning, 213-246. Oxford: Berg Publishers. 
Johnson, Mark. 2008. The meaning of the body: Aesthetics of human understanding. Chicago: University of Chicago Press.

Kissel, Marc \& Agustín Fuentes. 2017. Semiosis in the Pleistocene. Cambridge Archaeological Journal 27(3). 397-412.

Klein, Richard G. 2000. Archeology and the evolution of human behavior. Evolutionary Anthropology: Issues, News, and Reviews 9. 17-36.

Knappett, Carl. 2005. Thinking through material culture: An interdisciplinary perspective. Philadelphia: University of Pennsylvania Press.

Krueger, Joel. 2014. Varieties of extended emotions. Phenomenology and the Cognitive Sciences 13(4). 533-555.

Kuhn, Steven L., Mary C. Stiner, David Reese \& Erksin Güleç. 2001. Ornaments of the earliest Upper Paleolithic: New insights from the Levant. Proceedings of the National Academy of Sciences 98. 7641-7646.

Kuhn, Steven L. \& Mary C. Stiner. 2007. Paleolithic ornaments: Implications for cognition, demography and identity. Diogenes 54. 40-48.

Kuhn, Steven L. 2014. Signaling theory and technologies of communication in the Paleolithic. Biological Theory 9. 42-50.

Laland, Kevin N., Blake Matthews \& Marcus W. Feldman. 2016. An introduction to niche construction theory. Evolutionary Ecology 30(2). 191-202.

Lefebvre, Martin. 2007. Peirce's esthetics: A taste for signs in art. Transactions of the Charles S. Peirce Society 43. 319-344.

Malafouris, Lambros. 2008. Beads for a plastic mind: The 'Blind Man's Stick' (BMS) hypothesis and the active nature of material culture. Cambridge Archaeological Journal 18. 401-414.

Malafouris, Lambros. 2010. Metaplasticity and the human becoming: Principles of neuroarchaeology. Journal of Anthropological Sciences 88. 49-72.

Malafouris, Lambros. 2011a. Comment on "The Still Bay and Howiesons Poort, 77-59 ka: Symbolic material culture and the evolution of the mind during the African Middle Stone Age" by Christopher S. Henshilwood \& Benoît Dubreuil. Current Anthropology 52. 385-386.

Malafouris, Lambros. 2011b. The aesthetics of material engagement. In Riccardo Manzotti (ed.), Situated aesthetics: Art beyond the skin, 123-139. Exeter, NH: Imprint Academic.

Malafouris, Lambros. 2013. How things shape the mind: A theory of material engagement. Cambridge, MA: MIT Press.

Malafouris, Lambros. 2014. Creative thinging: The feeling of and for clay. Pragmatics \& Cognition 22(1). 140-158.

Malafouris, Lambros. 2015. Metaplasticity and the primacy of material engagement. Time and Mind 8(4). 351-371.

Malafouris, Lambros. 2016. On human becoming and incompleteness: A material engagement approach to the study of embodiment in evolution and culture. In Gregor Etzelmüller \& Christian Tewes (eds.), Embodiment in evolution and culture, 289- 306. Heidelberg: Mohr Siebeck.

Manzotti, Riccardo (ed.). 2011. Situated aesthetics: Art beyond the skin. Exeter, NH: Imprint Academic.

March, Paul Louis. 2019. Playing with clay and the uncertainty of agency. A Material Engagement Theory perspective. Phenomenology and the Cognitive Sciences 18(1). 133-151.

Mayr, Franz. 1907. Language of colours amongst the Zulus expressed by their bead-work ornaments; and some general notes on their personal adornments and clothing. Annals of the Natal Government Museum 1. 159-165. 
Mehra, K. L., K. C. Kanodia \& R. N. Srivastava. 1975. Folk uses of plants for adornment in India. Economic Botany 29. 39-46.

Menary, Richard. 2014. The aesthetic niche. British Journal of Aesthetics 54(4). 471-475.

Noble, William \& lain Davidson. 1996. Human evolution, language and mind: A psychological and archaeological inquiry. Cambridge: Cambridge University Press.

Nowell, April. 2010. Defining behavioral modernity in the context of Neandertal and anatomically modern human populations. Annual Review of Anthropology 39. 437-452.

Odling-Smee, John, Kevin N. Laland \& Marcus W. Feldman. 2003. Niche construction: The neglected process in evolution. Princeton: Princeton University Press.

O’Regan, J. Kevin \& Alva Noë. 2001. A sensorimotor approach to vision and visual consciousness. Behavioral and Brain Sciences 24. 883-975.

Oyama, Susan, Paul E. Griffiths \& Russell D. Gray. 2001. Introduction: What is developmental systems theory? In Susan Oyama, Paul E. Griffiths \& Russell D. Gray (eds.), Cycle of contingency: Developmental systems and evolution, 1-11. Cambridge, MA: MIT Press.

Parker, Kelly. 2017. Foundations for semeiotic aesthetics: Mimesis and iconicity. In Kathleen A. Hull \& Richard Kenneth Atkins (eds.), Peirce on perception and reasoning: From icons to logic, 61-73. New York \& London: Routledge.

Peirce, Charles S. 1931-1966. The collected papers of Charles S. Peirce, 8 vols., C. Hartshorne, P. Weiss \& A. W. Burks (eds.). Cambridge: Harvard University Press. [Reference to Peirce's papers will be designated $\mathrm{CP}$ followed by volume and paragraph number.]

Penny, Simon. 2017. Making sense: Cognition, computing, art, and embodiment. Cambridge, MA: MIT Press.

Pettitt, Paul. 2011. The living as symbols, the dead as symbols: Problematising the scale and pace of hominin symbolic evolution. In Christopher Henshilwood \& Francesco d'Errico. (eds.), Homo symbolicus: The dawn of language imagination and spirituality, 141-161. Amsterdam \& Philadelphia: John Benjamins Publishing Company.

Portera, Mariagrazia. 2016. Why do human perceptions of beauty change? The construction of the aesthetic niche. RCC Perspectives 5. 41-48.

Ranta, Michael. 2016. Art: On the evolutionary foundations of art and aesthetics. In David Dunér \& Göran Sonesson (eds.), Human Lifeworlds: The cognitive semiotics of cultural evolution, 123-144. Frankfurt am Main: Peter Lang Edition.

Renfrew, Colin. 2001. Symbol before concept: Material engagement and the early development of society. In Ian Hodder (ed.), Archaeological theory today, 122-140. Cambridge: Polity Press.

Reynard, Jerome P. \& Christopher S. Henshilwood. 2018. Using trampling modification to infer occupational intensity during the Still Bay at Blombos Cave, Southern Cape, South Africa. African Archaeological Review 35(1). 1-19.

Rossano, Matt J. 2010. Making friends, making tools, and making symbols. Current Anthropology 51. S89-S98.

Ruddle, Kenneth. 1973. The human use of insects: Examples from the Yukpa. Biotropica 5. 94-101.

Shea, John J. 2011. Homo sapiens is as Homo sapiens was: Behavioral variability versus "behavioral modernity" in Paleolithic archaeology. Current Anthropology 52. 1-35.

Simak, Evelyn \& Carl Dreibelbis. 2010. African beads: Jewels of a continent. Denver: Africa Direct.

Sinha, Chris. 2015. Ontogenesis, semiosis and the epigenetic dynamics of biocultural niche construction. Cognitive Development 36. 202-209. 
Slaby, Jan. 2014. Emotions and the extended mind. In Christian von Scheve \& Mikko Salmella (eds.), Collective emotions: Perspectives from psychology, philosophy, and sociology, 32-46. Oxford: Oxford University Press.

Sonesson, Göran. 2000. Ego meets Alter: The meaning of otherness in cultural semiotics. Semiotica 128 (3/4). 537-559.

Sonesson, Göran. 2006. The meaning of meaning in biology and cognitive science: A semiotic reconstruction. Sign System Studies 34. 135-213.

Sonesson, Göran. 2007. From the meaning of embodiment to the embodiment of meanings: A study in phenomenological semiotics. In Tom Ziemke, Jordan Zlatev \& Roslyn M. Frank (eds.), Body, language, and mind. Volume 1: Embodiment, 85-128. Berlin: Mouton de Gruyter.

Sonesson, Göran. 2010. From mimicry to mime by way of mimesis: Reflections on a general theory of iconicity. Sign System Studies 38. 18-66.

Sonesson, Göran. 2012. Semiosis beyond signs. On two or three missing links on the way to human beings. In Theresa Schilhab, Frederik Stjernfelt \& Terrence Deacon (eds.), The symbolic species evolved, 81-93. Dordrecht: Springer.

Sonesson, Göran. 2013a. The natural history of branching: Approaches to the phenomenology of Firstness, Secondness, and Thirdness. Signs and Society 1(2). 297-325.

Sonesson, Göran. 2013b. The picture between mirror and mind: From phenomenology to empirical studies in pictorial semiotics. In Klaus Sachs-Hombach \& Jörg R. J. Schirra (eds.), Origins of pictures: Anthropological discourses in image science, 270-310. Köln: Herbert von Halem Verlag.

Sonesson, Göran. 2013c. Preparations for discussing construcivism with a Martian (the second coming). In David Dunér, Joel Parthemore, Erik Persson \& Gustav Holmberg (eds.), The history and philosophy of astrobiology: Perspective on the human mind and extraterrestrial life, 185-200. Newcastle upon Tyne: Cambridge Scholars.

Sonesson, Göran. 2016. Lifeworlds: The cognitive semiotics of culture. In David Dunér \& Göran Sonesson (eds.), Human Lifeworlds: The cognitive semiotics of cultural evolution, 23-61. Frankfurt am Main: Peter Lang Edition.

Stephan, Achim, Sven Walter \& Wendy Wilutzky. 2013. Emotions beyond brain and body. Philosophical Psychology 27. 65-81.

Sterelny, Kim. 2012. The evolved apprentice: How evolution made humans unique. Cambridge, MA: MIT press.

Stiner, Mary C. 2014. Finding a common band-width: Causes of convergence and diversity in Paleolithic beads. Biological Theory 9. 51-64.

Strathern, Andrew \& Marilyn Strathern. 1971. Self-decoration in Mount Hagen. London: Duckworth.

Turner, Terrence S. 1980. The social skin. In Jeremy Cherfas \& Roger Lewin (eds.), Not work alone: A cross-cultural view of activities superfluous to survival, 112-140. London: Temple Smith.

Valsiner, Jaan. 2016. A semiotic approach to creativity: Resources for re-contextualization. In Vlad Petre Glăveanu (ed.), The Palgrave handbook of creativity and culture research, 189-204. London: Palgrave Macmillan.

Vanhaeren, Marian \& Francesco d'Errico. 2006. Aurignacian ethno-linguistic geography of Europe revealed by personal ornaments. Journal of Archaeological Science 33. 1105-1128. 
Vanhaeren, Marian, Francesco d'Errico, Chris Stringer, Sarah L. James, Jonathan A. Todd \& Henk K. Mienis. 2006. Middle Paleolithic shell beads in Israel and Algeria. Science 312. 1785-1788.

Vanhaeren, Marian, Francesco d'Errico, Karen L. van Niekerk, Christopher S. Henshilwood \& Rudolph M. Erasmus. 2013. Thinking strings: Additional evidence for personal ornament use in the Middle Stone Age at Blombos Cave, South Africa. Journal of Human Evolution 64. 500-517.

van Leeuwen, Edwin J. C., Katherine A. Cronin \& Daniel B. M. Haun. 2014. A group-specific arbitrary tradition in chimpanzees (Pan troglodytes). Animal Cognition 17(6). 1421-1425.

Wadley, Lyn. 2001. What is cultural modernity? A general view and a South African perspective from Rose Cottage Cave. Cambridge Archaeological Journal 11. 201-221.

Watts, Christopher. 2008. On mediation and material agency in the Peircean semeiotic. In Carl Knappett \& Lambros Malafouris (eds.), Material agency: Toward a non-anthropocentric approach, 187-207. New York: Springer.

Weiner, Annette B. 1988. The Trobrianders of Papua New Guinea. New York: Holt, Rinehart \& Winston.

White, Randall. 1989. Production complexity and standardisation in early Aurignacian bead and pendant manufacture: Evolutionary implications. In Chris Stringer \& Paul Mellars (eds.), The human revolution: Behavioural and biological perspectives on the origins of modern humans, 366-390. Edinburgh: Edinburgh University Press.

White, Randall. 2007. Systems of personal ornamentation in the Early Upper Palaeolithic: Methodological challenges and new observations. In Paul Mellars, Katie Boyle, Ofer Bar-Yosef \& Chris Stringer (eds.), Rethinking the human revolution: New behavioural and biological perspectives on the origin and dispersal of modern human, 287-302. Cambridge: McDonald Institute for Archaeological Research.

Williams, Sarah. 1987. An 'archae-logy’ of Turkana beads. In Ian Hodder (ed.), The archaeology of contextual meanings, 31-38. Cambridge: Cambridge University Press.

Xenakis, loannis \& Argyris Arnellos. 2015. Aesthetics as an emotional activity that facilitates sense-making: Towards an enactive approach to aesthetic experience. In Alfonsiva Scarinzi (ed.), Aesthetics and the embodied mind: Beyond art theory and the Cartesian mind-body dichotomy, 245-259. Dordrecht \& New York: Springer. 